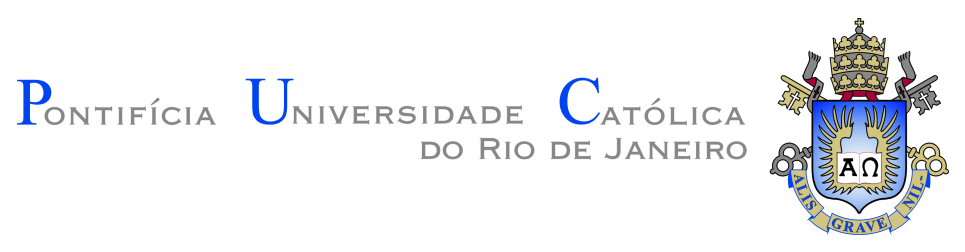

Marcela Carvalho Ferreira de Mello

\title{
Anchored Expectations and the Term Structure of Bond Yields
}

Dissertação de Mestrado

Dissertation presented to the Programa de Pós-graduação em Economia of PUC-Rio in partial fulfillment of the requirements for the degree of Mestre em Economia.

Advisor: Prof. Carlos Viana de Carvalho 


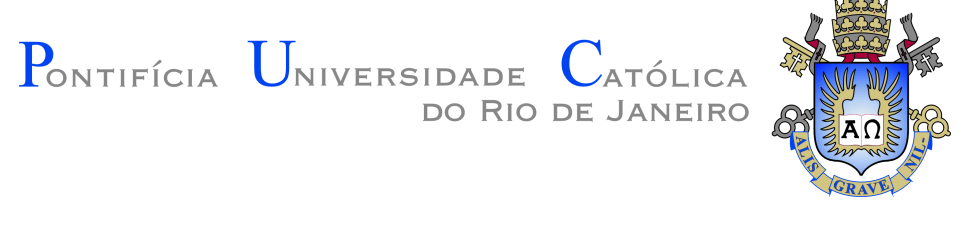

Marcela Carvalho Ferreira de Mello

\title{
Anchored Expectations and the Term Structure of Bond Yields
}

Dissertation presented to the Programa de Pós-graduação em Economia of PUC-Rio in partial fulfillment of the requirements for the degree of Mestre em Economia. Approved by the Examination Committee.

\author{
Prof. Carlos Viana de Carvalho \\ Advisor \\ Departamento de Economia - PUC-Rio
}

Prof. Marco Bonomo

Insper Instituto de Ensino e Pesquisa - Insper

Prof. Stefano Eusepi

The University of Texas at Austin - UT Austin

Rio de Janeiro, April 18th, 2019 
All rights reserved.

\section{Marcela Carvalho Ferreira de Mello}

B.A., Economics, Universidade de São Paulo (USP), 2015.

Bibliographic data

Carvalho Ferreira de Mello, Marcela

Anchored Expectations and the Term Structure of Bond Yields / Marcela Carvalho Ferreira de Mello; advisor: Carlos Viana de Carvalho. - Rio de janeiro: PUC-Rio, Departamento de Economia, 2019.

v., 58 f: il. color. ; $30 \mathrm{~cm}$

Dissertação (mestrado) - Pontifícia Universidade Católica do Rio de Janeiro, Departamento de Economia.

Inclui bibliografia

1. Economia - Teses. 2. Macroeconomia - Teses. 3. Estrutura a Termo;. 4. Expectativas Ancoradas;. 5. Expectativas de Inflação.. I. Viana de Carvalho, Carlos. II. Pontifícia Universidade Católica do Rio de Janeiro. Departamento de Economia. III. Título. 


\section{Acknowledgments}

I thank God for showing me the way, even in the darkest times. I thank my parents, Ana Helena and Marcelo, my sister, Marina, and my brother, Felipe, for their love, understanding, and support throughout my entire life. I thank my boyfriend, Fernando, for giving me the strength to overcome the obstacles in the way, for the long and insightful talks, and for his extraordinary patience, caring, and help during this last year. I would not have finished this project without him.

I too have no words to thank my advisor, Prof. Carlos Viana de Carvalho, for his incredible guidance, encouragement, and dedication to this project, and Prof. Ruy Ribeiro for his support and helpful insights. Finally, I thank Prof. André Chagas, who inspired me to pursue an academic career in the first place.

This study was partly financed by FAPERJ and by the Coordenação de Aperfeiçoamento Pessoal de Nível Superior - Brasil (CAPES) - Código de Financiamento 001. The financial support from PUC-Rio is also gratefully acknowledged. 


\section{Abstract}

Carvalho Ferreira de Mello, Marcela; Viana de Carvalho, Carlos (Advisor). Anchored Expectations and the Term Structure of Bond Yields. Rio de Janeiro, 2019. 58p. Dissertação de Mestrado - Departamento de Economia, Pontifícia Universidade Católica do Rio de Janeiro.

The relation between asset prices, monetary policy expectations, and macroeconomic data releases has long been assessed by the literature. This dissertation addresses the implications of the anchoring or unanchoring of long-run inflation expectations, as a stance of monetary policy, to the term structure of bond yields. In particular, it aims to understand how this mechanism is connected to the time-varying pattern of both the volatility of nominal yields and their sensitivity to macroeconomic surprises. To that matter, we present a New-Keynesian model with two main characteristics. First, agents have subjective beliefs instead of rational expectations. They learn about the inflation target set by the central bank and their expectations may become anchored or unanchored over time, given the state of the economy. Second, agents face time-varying risk aversion. The model has one main prediction: the sensitivity of the term structure to inflation surprises is not only time-varying, but state-dependent.

\section{Keywords}

Term Structure; Anchored Expectations; Inflation Expectations. 


\section{Resumo}

Carvalho Ferreira de Mello, Marcela; Viana de Carvalho, Carlos. Ancoragem de Expectativas e a Estrutura a Termo da Taxa de Juros. Rio de Janeiro, 2019. 58p. Dissertação de Mestrado Departamento de Economia, Pontifícia Universidade Católica do Rio de Janeiro.

A relação entre preços de ativos, expectativa de política monetária, e liberação de dados macroeconômicos tem sido avaliada pela literatura há bastante tempo. Essa dissertação estuda as implicações da ancoragem das expectativas de longo prazo de inflação, como instrumento de política monetária, para a estrutura a termo das taxas de juros. Particularmente, este trabalho objetiva entender como esse mecanismo se conecta ao padrão de variabilidade temporal de ambas a volatilidade dos retornos nominais e a sensibilidade dos mesmos a novidades macroeconômicas. Tendo isso em vista, um modelo Novo-Keynesiano com duas principais características é apresentado. Primeiro, os agentes possuem crenças subjetivas ao invés de expectativas racionais. Eles aprendem sobre o target de inflação definido pelo banco central e suas expectativas podem se tornar ancoradas ou desancoradas, dado o estado da economia. Segundo, a aversão ao risco dos consumidores varia ao longo do tempo. O modelo possui uma principal predição: a sensibilidade da estrutura a termo da taxa de juros com relação a supresas de inflação não apenas varia no tempo, mas depende do estado da economia.

\section{Palavras-chave}

Estrutura a Termo; Expectativas Ancoradas; Expectativas de Inflação. 


\section{Table of contents}

1 Introduction $\quad 11$

2 Model $\quad 18$

2.1 Basic Setting 18

2.2 Rational Expectations 20

2.3 Subjective Beliefs 23

2.3.1 Solution under Subjective Beliefs 23

2.3.2 Expectation Formation Process $\quad 27$

$\begin{array}{ll}\text { 2.3.3 Term Structure } & 29\end{array}$

3 Estimation $\quad 32$

3.1 The Approximate Model 32

3.2 Data and Calibrated Parameters 33

3.3 Estimated Parameters 35

4 State-Dependent Sensitivity of the Term Structure 40

4.1 Impulse Response Function $\quad 40$

4.2 Simulations 42

5 Conclusion $\quad 46$

A Empirical Evidence $\quad 52$

B Approximate Model $\quad 53$

B.1 Deriving the Approximate Model $\quad 53$

B.2 The Measurement Equation 54

B.3 Term Premia, Simulations and Impulse Response Function 55

B.4 Structural Innovations (Smoothed Predictions) 57 


\section{List of figures}

Figure 1.1 Empirical Evidence, US, Quarterly Data 15

Figure 3.1 Fit of the Model to Observed Data 38

$\begin{array}{lll}\text { Figure } 3.2 & \text { Learning Gain } & 39\end{array}$

Figure 4.1 Volatility Curves of Forward Rates, Response to Different Shocks. The colored numbers show the ratio between the volatility of the forward-rates ending, respectively, in 10 and in 2 years. The values in bold represent this ratio for the approximate model.

Figure A.1 Empirical Evidence, US, Daily Data 52

Figure B.1 Term Premia, Moments (1,000 simulations of 500 periods each)

Figure B.2 Term Premia, Response to Different Shocks 56

Figure B.3 Structural Shocks, Estimation 58 


\section{List of tables}

Table 3.1 Data and Sources 34

Table 3.2 Zero Lower Bound, periods 35

Table 3.3 Calibrated Parameters $\quad 35$

Table 3.4 Estimated Parameters 36

Table 4.1 Volatility of Forward Rates 44

Table 4.2 Pass-Through Coefficients 45 


\section{List of Abreviations}

SDF - Stochastic Discount Factor

SML - Simulated Maximum Likelihood

US - United States

ZLB - Zero Lower Bound 


\section{Introduction}

In the past decades, great effort in empirical literature has been devoted to studying the relation between asset prices, monetary policy expectations, and macroeconomic data releases. In particular, the excess sensitivity puzzle, that concerns the fact that yields respond much strongly to macroeconomic news than predicted by classic rational expectations paradigm, has been extensively assessed. ${ }^{1}$ Because the anchoring of inflation expectations is a central notion to monetary policy, research has also focused on comprehending the connection between this mechanism and nominal yield sensitivity to news. Nonetheless, the standard New-Keynesian framework, with completely rational agents, fails to provide a good fit for the term structure of interest rates and is not able to generate the level of volatility, nor the excess sensitivity observed in the data. In this sense, both moving to an imperfect knowledge framework that features learning processes ${ }^{2}$ or introducing a time-varying risk premium have proven successful to address at least partially those problems. ${ }^{3}$ Despite these theoretical advances, however, little has been done to explain how and why this link between monetary policy and the sensitivity of the term structure changes over time.

This dissertation presents a conceptual framework with endogenous anchoring of long-term inflation expectations to study the implications of changes in those expectations to the term structure of government bond yields. Specifically, it aims to explain how is the anchoring of inflation expectations connected to the time-varying pattern of the sensitivity of the term structure to short-run movements. The core idea in this dissertation can be summarized in a simple example. Suppose that the only factor that affects the volatility of longer yields is the long-term inflation expectation. Now, suppose that exogenous shocks hit the economy, yielding a large and positive inflation surprise. How is the term structure of interest rates affected? If expectations are anchored, in the sense that agents believe that the monetary authority can stabilize

${ }^{1}$ This literature traces back to Shiller (1979).

${ }^{2}$ See Piazzezi (2015), Sinha (2016), Laubach et al. (2007), Rudebusch and Wu (2008), Cogley (2005), Fuhrer (1996), Dewachter and Lyrio (2008), and Dewatcher et al. (2011), among others.

${ }^{3}$ See Rudebusch and Swanson (2008), Rudebusch and Swanson (2012), Dew-Becker (2014), among others 
the economy in the short-run, then the yields on bonds of longer maturities should not react. However, if expectations are unanchored in that agents do not expect the monetary authority to stabilize the economy in the short-run, then the yields on bonds of longer maturities should react, as it is expected that the monetary authority must change the interest rate in the longer run.

This simple, intuitive idea has actually motivated an extensive literature on news regressions (see Gürkaynak et al., 2005; Ehrmann et al., 2011; Gürkaynak et al., 2010, 2007a; Beechey, 2006), whose main objective is to test whether expectations are anchored or not when looking at the data. Nonetheless, from a theoretical standpoint, the models proposed in the literature to explain this behavior, so far, do not capture the intuition that the interrelation between yields and monetary policy should be ultimately time-varying, for the economy should evolve differently in periods with anchored or with unanchored inflation expectations. Besides this theoretical motivation, an important motive behind this dissertation is that the proposed structural model, conditional on being validated with the data, enables one to produce counterfactual scenarios to assess the impacts that monetary policy, through the anchoring of expectations, may have had on various events. This allows for several relevant questions. For instance, regarding the recent inversion in the US yield curve, how would the curve behave had long-run inflation expectations been better or worse anchored?

Given the dependency of nominal yield sensitivity to inflation surprises on whether long-run inflation expectations are anchored or not, capturing yield sensitivity should be closely connected to modelling the anchoring of expectations. Although many models account for expectations not being firmly anchored by introducing an unknown inflation target that has to be learnt with constant gains, ${ }^{4}$ other models, such as Carvalho et al. (2017) and Busetti et al. (2017), explicitly account for the anchoring of expectations by considering that the learning process is somewhat endogenous. For instance, Busetti et al. (2017) consider that agents have to choose, based on a specific selection mechanism, ${ }^{5}$ between actually believing in the inflation target announced by the monetary authority or relying on a "naïve" model to make inflation forecasts, while Carvalho et al. (2017) include an endogenous switch between constant and decreasing gain learning, allowing agents to track monetary policy regime changes. Note, however, that these last papers are not concerned with the term structure of interest rates. Rather, their objective is to address the mechanisms

\footnotetext{
${ }^{4}$ Examples are Gürkaynak et al. (2005), Sinha (2016), Dewachter and Lyrio (2008), among others.

${ }^{5}$ Agents tend to select strategies that do better than the population average while discarding those that do worse (Busetti et al., 2017).
} 
of anchoring of inflation expectations.

Having that in sight, one of our main contributions is to address the matter of the sensitivity of the term structure of bond yields to surprises in a framework that explicitly models the anchoring of inflation expectations. In particular, this dissertation presents a simple New-Keynesian model with recursive preferences and time-varying risk aversion, and assumes that agents hold subjective beliefs instead of rational expectations. The only source of uncertainty is the central bank's inflation target, which is assumed not to be known by agents. Importantly, this framework rationalizes the excess sensitivity of interest rates to macroeconomic surprises by introducing the learning mechanism proposed in Carvalho et al. (2017). The model is characterized by an endogenous switch between learning regimes that depends on past forecast errors, thus accounting for state-dependent anchoring of inflation expectations. If the economic environment is unstable, in the sense that large forecast errors with the same sign are sequentially realized, agents switch learning regimes. Hence, inflation expectations become unanchored whenever the inflation target forecast error is large enough (in absolute value). ${ }^{6}$ The model produces a main testable prediction, namely that the sensitivity of the yield curve to inflation surprises is not only time-varying, but, rather, state-dependent. We discuss this implication by analyzing results on simulations and on impulse response functions. Furthermore, we estimate the model by Simulated Maximum Likelihood (SML) using data from the US on both the term structure of government bond yields and on inflation expectations.

In general, there are three factors that affect the volatility of longer nominal yields: real interest rate expectations, time-varying risk premia, and long-run inflation expectations (see Crump et al., 2016; Beechey and Wright, 2009; Beechey, 2006; Cochrane and Piazzezi, 2005). Although this dissertation focuses solely on the last factor, previous literature has pointed to the relevance of the first two. For instance, Beechey (2006), relying on an affine term structure modelling, emphasizes the role of volatile term premiums on the sensitivity of forward rates to economic news in the US, while Crump et al. (2016), with a different methodology, ${ }^{7}$ find that term premiums are the dominant source of variation in bond yields. In turn, Beechey and Wright (2009) find that for news announcements about real economic activity, such as nonfarm payrolls, the vast majority of the sensitivity is concentrated in real rates.

${ }^{6}$ This may be related to the discussion in Ascari et al. (2017).

${ }^{7}$ The authors estimate a reduced-form VAR with shifting endpoints for the real output growth rate, the inflation, and the short-term interest-rate, thus capturing learning and structural changes. 
To control for time-varying risk premia, we follow Dew-Becker (2014) in that we present a model that features agents with recursive preferences and time-varying risk aversion. Moreover, the essentially affine method for deriving the model, proposed in Dew-Becker (2012), is also used. An interesting feature of our framework is that the term premia are state dependent, in the sense that term premiums tend to be more volatile when inflation expectations are unanchored. This relates to Wright (2011), who finds evidence in support of bond risk premia reflecting mainly uncertainty about future inflation. The main limitation of our theoretical framework, however, is that it does not control for real rate expectations, a matter that is left for future research.

In view of these considerations, this dissertation also contributes to a large literature that looks at the failure of the basic New-Keynesian model in explaining the term structure of interest rates. This literature can be generally classified in two groups. The first maintains the rational expectations assumption, but resorts to higher order approximations, additional features (e.g., consumption habit or time-varying exogenous inflation target), or appends a term structure with time-varying prices of risk to improve the simple NewKeynesian framework. Examples are Wu (2006), Bekaert et al. (2010), Rudebusch and Wu (2008), Rudebusch and Swanson (2012), Dew-Becker (2014), among many others. ${ }^{8}$ The second group is composed of papers that step away from the rational expectations hypothesis and assume that agents have to learn about certain variables or parameters over time. Examples are Gürkaynak et al. (2005), Laubach et al. (2007), Dewachter and Lyrio (2008), Sinha (2016), among others. The present dissertation contributes theoretically in that it combines elements of the aforementioned literature in one common microfounded framework and offers an explanation to why the interrelation between monetary policy and the nominal yield curve should endogenously change over time. ${ }^{9}$ As our results suggest, this combination enables the model to explain some facts that none of its features, alone, is able to.

Panel (A) from Figure 1.1 presents volatility curves of one-year forwardrates ending in $k$ years, $k=2,3, \ldots, 9$, in the US for two periods. ${ }^{10}$ These

${ }^{8}$ See, for instance, Rudebusch and Swanson (2008), Hördahl et al. (2008), Emiris (2006), De Graeve et al. (2009), and Garcia et al. (2014).

${ }^{9}$ Some papers, such as Aguilar and Vazquez (2018) and Dewatcher et al. (2011), have tried to combine these strands of literature. The former introduces term premium shocks in the bond pricing equations of each maturity and considers that agents use simple forecasting equations to learn about unknown parameters, while the latter appends an affine term structure with time-varying prices of risk and assumes constant-gain learning. In both, however, there is no discussion regarding the anchoring of inflation expectations, nor do they impose consistency between the aggregate demand relation and the pricing kernel.

${ }^{10}$ Note that by volatility curve we refer to a plot of standard-deviation of forward rates against their ending year, and by one-year forward rate ending in $k$ years we mean the implicit rate between a $k$-year bond and a $(k+1)$-year bond. 
periods were defined based on the results of Carvalho et al. (2017). The first, represented by the red line, goes from 1975 to 1995 and is a period of unanchored inflation expectations, while the second, in green, that goes from 1996 to 2006, is a period of anchored expectations. The first feature that stands out in Panel (A) is that forward rates are much more volatile in the period of instability of inflation expectations (red line) than in that of stability (green line). Second, the red line appears to be much flatter than the green one, meaning that not only is the overall volatility of forward rates larger, but that rates ending in far-ahead periods are much more volatile relatively to shorter rates when inflation expectations are unstable. This can be further seen from the numbers in parenthesis in Panel (A). Those numbers represent the ratio between the standard-deviation on a rate ending in 10 years and that of a rate ending in 2 years, and give a sense of the slope of the curves. Notice that the number related to the red line, 0.6 , is much larger than the one associated with the green line, 0.2 , indicating that the red one is flatter (with a ratio closer to 1). Similar patterns seem to hold for daily data (see Figure A.1 in Appendix A).

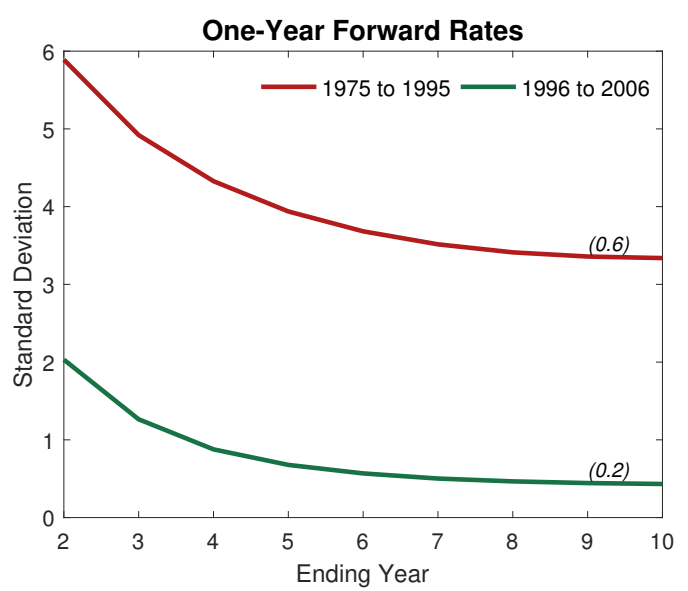

Panel (A).

() ratio between the standard deviation of the one-year forward rates ending in 10 and in 2 years. Quarterly data, jan/1975 to dec/2006.

Source: US Nominal Zero-Coupon Yields - Gürkaynak et al. (2007b). Forward Rates - author's estimates.

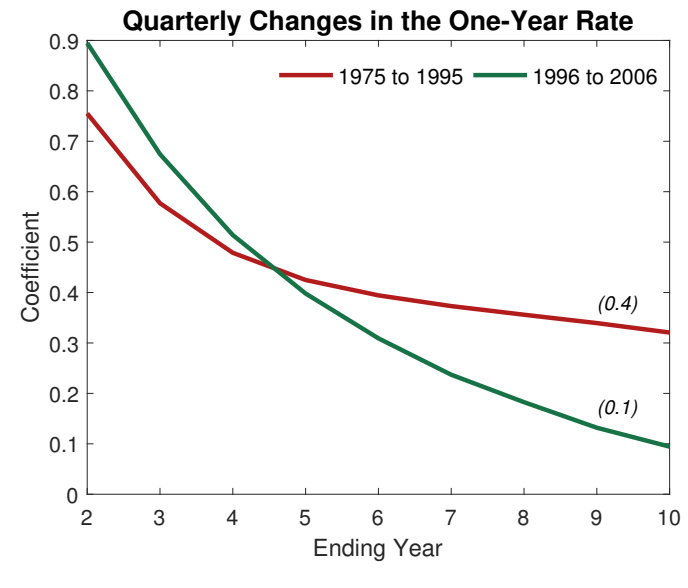

Panel (B).

() ratio between the coefficients estimated in the regressions for forward rates ending, respectively, in 10 and in 2 years. Dependent Variable: quarterly changes in one-year forward ates (different ending years). Regressor: quarterly changes in the one-year spot rate. Source: author's estimates.

Figure 1.1: Empirical Evidence, US, Quarterly Data

Panel (B), also from Figure 1.1, in turn, presents the results from passthrough regressions estimated with quarterly changes in forward rates as dependent variable and quarterly changes in the spot one-year rate as regressor. Specifically, we plot the slope coefficients estimated in those regressions against the possible ending years of forward rates. Again, the red line concerns the period of less stable inflation expectations in the US, whereas the green line is associated with more stable expectations. Interestingly, the coefficients 
associated with the period 1996-2006 are larger than those from the period 1975-1995 for shorter rates. However, for far-ahead ending years, coefficients are larger when inflation expectations are unstable. Once more, though less pronounced than in Panel (A), the red coefficient line is flatter than the green one, as the ratio in parenthesis is larger for the former (0.4 against 0.1). Again, a similar pattern seems to hold for daily data (see Figure A.1 in Appendix A).

Results on simulations can be summarized in four main points. First, even when introducing time-varying risk aversion in the simple New-Keynesian model, the rational expectations assumption fails to generate patterns of volatility of forward rates and of pass-through regression coefficients consistent with the data. Specifically, the volatility is always low, with a ratio (equivalent to those on Panel (A)) of about 0.02, and the pass-through coefficients for farahead forward rates are always very close to zero. Second, when expectations are anchored, although results resemble those under rational expectations, overall volatility and the mentioned ratios are always larger than rational expectations counterpart. Third, when expectations are unanchored, besides overall larger volatility, the model produces flatter volatility and coefficient curves compared to the previous cases. Fourth, because of the shifts between anchored and unanchored expectations, the model under subjective beliefs is able to explain the time-varying and, at least seemingly, state-dependent pattern of curves in Figure 1.1. More specifically, even though a model with only constant-gain learning also generates more volatile forward rates, statedependency of inflation expectations is necessary to produce time-variability in the conditional moments of the term structure.

Regarding the impulse response functions, the main insight is that the sensitivity of the term structure to inflation surprises is state-dependent: whenever expectations are unanchored, the volatility of far-ahead forward rates generated in response to an inflation surprise is much larger than that produced with more stable inflation expectations. In particular, this conditional response is comparable to the results of news regressions, and implies that the slope coefficients in those regressions should vary over time conditional on the state of the economy.

The evidence in Figure 1 and the results from simulations and impulse response functions relate to Hanson and Lucca (2017), who also find that there is an overall decrease in the sensitivity of longer rates to shorter ones (in lower data frequencies) since 2000. Even though the discussion in the paper focuses on how this sensitivity varies across data frequencies for a given maturity, the authors argue that the observed fall in the sensitivity of longer rates could be due to a decrease in the volatility of a so-called persistent component of short 
rates post-2000. Here, such component would be the inflation expectations, that, according to the results in Carvalho et al. (2017), should be anchored since the mid-1990s.

The aforementioned results are also in line with a broad finance literature which points out that macro-factors are important to explain the term structure of bond yields. Examples are Kozicki and Tinsley (2001), Ang and Piazzesi (2003), Garcia and Luger (2012), Ireland (2015), among many others. ${ }^{11}$ Furthermore, results are connected to those of a literature that introduces monetary policy regime shifts to address the time-varying relation between monetary policy and interest rates (see Ang et al. (2011) and Filipova et al. (2014)). ${ }^{12}$ We differentiate from this literature in that we present a structural model embedded with another source of state-dependency in yields, namely state-dependent anchoring of inflation expectations. Instead of assuming that the reaction function of the central bank actually changes over time, which has been a matter of controversy, ${ }^{13}$ this dissertation simply hypothesizes that agents are not sure about the inflation target. Such uncertainty does encompass the case of actual regime changes, but also accounts for other situations, for instance, a constant unannounced inflation target, or a scenario with agents that do not believe in the announced target.

The rest of the dissertation is organized as follows: in Chapter 2, the conceptual framework is presented, while Chapter 3 discusses the estimation of the model, and Chapter 4 assesses the results from simulations. Chapter 5 concludes.

\footnotetext{
${ }^{11}$ See, for instance, Dewatcher and Lyrio (2006), Dewatcher et al. (2006), Hördahl et al. (2006), and Piazzesi and Schneider (2007).

${ }^{12}$ See also Amisano and Tristani (2009), Orphanides and Wei (2012), and Bikbov and Chernov (2013).

${ }^{13}$ See Ang et al. (2011) for a discussion.
} 


\section{Model}

\section{1}

\section{Basic Setting}

A continuum of households $i \in[0,1]$ consume a consumption index, $C_{i, t}$, consisting of $f \in[0,1]$ products and supply labor hours, $h_{i, t}$, to the monopolistically competitive firms, who face a Rotemberg (1982) problem. Asset markets are incomplete and households have access to $N$ riskless bonds, which are issued by the fiscal authority in zero net supply. Households optimally choose their consumption and their holdings of each $\tau$-period bond, given their own subjective beliefs $\hat{E}_{t}^{i}$. Each agent $i$ in the continuum has recursive preferences over consumption and leisure,

$$
V_{i, t}=\left\{(1-\beta) U_{i, t}+\beta\left[\hat{E}_{t}^{i} V_{i, t+1}^{1-\alpha_{t}}\right]^{\frac{1-\rho}{1-\alpha_{t}}}\right\}^{\frac{1}{1-\rho}}
$$

where the period utility function is ${ }^{1}$

$$
U_{i, t} \equiv\left[\frac{C_{i, t}^{1-\rho}}{1-\rho}+\phi_{h} \frac{\left(\bar{H}-h_{i, t}\right)^{\alpha_{h}(1-\rho)}}{1-\rho}\right] \xi_{t}
$$

and: $\bar{H}$ is the maximum number of hours that a household may work; the discount factor is assumed to satisfy $0<\beta<1$; and the parameters respect $0<\rho<1, \alpha_{h}>0$, and $\phi_{h}>0$. In addition, $\xi_{t}$ is an aggregate preference shock that, in logarithm, follows a stationary process with mean zero. Following DewBecker (2014), the coefficient of relative risk aversion, $\alpha_{t}$, is allowed to vary over time, and is affected by exogenous shocks. The consumption index, $C_{i, t}$, and its respective price, $P_{t}$, are given by

$$
C_{i, t} \equiv\left[\int_{0}^{1} C_{i, t}(f)^{\frac{\theta_{t}-1}{\theta_{t}}} d f\right]^{\frac{\theta_{t}}{\theta_{t}-1}} \text { and } P_{t} \equiv\left[\int_{0}^{1} P_{t}(f)^{1-\theta_{t}} d f\right]^{\frac{1}{1-\theta_{t}}}
$$

${ }^{1}$ We follow the same functional form proposed in Dew-Becker (2014), but add an aggregate preference shock in order to maintain comparability with the simple model in Carvalho et al. (2017). 
where $C_{i, t}(f)$ and $P_{t}(f)$ denote household $i$ 's consumption and the price of the good $f$. The elasticity of demand for differentiated goods is given by an exogenous process that satisfies $\theta_{t}>1$, with mean $\bar{\theta}$. Finally, $\hat{E}_{t}^{i}$ denotes subjective beliefs of household $i$ and is assumed to satisfy $\hat{E}_{t}^{i} \hat{E}_{T}^{i}=\hat{E}_{t}^{i}$ for all $T \geq t$.

Let $B_{i, t}(\tau)$ denote the net holdings of a bond of $\tau$-period maturity at time $t$ by household $i$, and let $P_{\tau, t}^{B}$ denote the price of a $\tau$-period bond at time $t$ (this is the bond that matures in period $t+\tau$ ). The flow budget constraint of household $i$ is given $\mathrm{by}^{2}$ :

$$
P_{t} C_{i, t}+\sum_{\tau=1}^{N} P_{\tau, t}^{B} B_{i, t}(\tau) \leq B_{i, t-1}(1)+\sum_{\tau=2}^{N} P_{\tau-1, t}^{B} B_{i, t-1}(\tau)+P_{t} Y_{i, t}
$$

where $Y_{i, t}$ is the period real income of households. Households receive income in the form of wages, $w_{t}(f)$, for labour supplied in the production of each good $f$, and are assumed to own an equal part of each firm, thus, receiving a common share of profits $\Pi_{t}(f)$ from the sale of each firm's good $f{ }^{3}$ At last, under the assumption of a symmetrical equilibrium where households hold the same subjective beliefs, the real stochastic discount factor is given by

$$
\Lambda_{t+1} \equiv \frac{\partial V_{t} / \partial C_{t+1}}{\partial V_{t} / \partial C_{t}}=\left(\beta \frac{U_{C, t+1}}{U_{C, t}}\right)^{\frac{1-\alpha_{t}}{1-\rho}} R_{U, t+1}^{\frac{\rho-\alpha_{t}}{1-\alpha_{t}}}
$$

where $R_{U, t+1}$ is the return on an asset that pays $U_{t} U_{C, t}^{-1}$ as its dividend in each period.

Following Carvalho et al. (2017), a continuum of monopolistically competitive firms, $f \in[0,1]$, face a Rotemberg (1982) price-setting problem. Given subjective beliefs $\hat{E}_{t}^{f}$, each firm $f \in[0,1]$ maximizes the expected present discounted value of profits

$$
\hat{E}_{t}^{f} \sum_{T=t}^{\infty} \Lambda_{t, T} \Pi_{T}(f)
$$

${ }^{2}$ We assume that the No-Ponzi constraint,

$$
\lim _{j \rightarrow \infty} \hat{\mathbb{E}}_{t}^{i} R_{t, t+j+1} W_{i, t+j+1} \geq 0
$$

where $R_{t, t+j}=\prod_{k=1}^{j} P_{1, t+k-1}^{B}$ and $W_{i, t} \equiv B_{i, t-1}(1)+\sum_{\tau=2}^{N} P_{\tau-1, t}^{B} B_{i, t-1}(\tau)$, holds.

${ }^{3}$ Therefore, household $i$ 's period nominal income is determined as

$$
P_{t} Y_{i, t}=\int_{0}^{1}\left(w_{t}(f) h_{i, t}(f)+\Pi_{t}(f)\right) d f .
$$


by choice of $P_{t}(f)$ given demand and profit functions ${ }^{4}$

$$
\begin{aligned}
& Y_{t}(f)=\left(\frac{P_{t}(f)}{P_{t}}\right)^{-\theta_{t}} Y_{t} \\
& \Pi_{t}(f)=Y_{t}(f)\left(\frac{P_{t}(f)}{P_{t}}-S_{t}\right)-\frac{\phi_{s}}{2}\left(\frac{P_{t}(f)}{P_{t-1}(f)}-e^{\bar{\pi}^{p}}\right)^{2},
\end{aligned}
$$

for all $T \geq t$, where $P_{t}$ and $Y_{t}$ give the aggregate level of prices and output in period $t$, and $S_{t}$ a real marginal cost function. The quadratic costs of price adjustment, scaled by $\phi_{s}>1$, are determined by price movements relative to an inflation index, which in logs is given by $\bar{\pi}^{p}=\gamma \pi_{t-1}$, where $\pi_{t-1}=\ln \left(\frac{P_{t-1}}{P_{t-2}}\right)$ is the previous-period's aggregate inflation rate and $0<\gamma<1$ measures the degree of price indexation. Finally, $\Lambda_{t, T}$ is the real stochastic discount factor that, in the non-stochastic steady state, takes the value $\beta^{T-t}$, for all $T \geq t$.

To close the model, we consider that agents hold the same subjective beliefs, $\hat{E}_{t}^{f}=\hat{E}_{t}^{i}=\hat{E}_{t}$, and assume that the central bank follows a Taylor rule

$$
\frac{R_{t}}{\bar{R}}=\hat{E}_{t}\left[\Pi_{t+1}\left(\Pi_{t+1} e^{-\bar{\pi}_{t+1}^{p}}\right)^{\phi_{\pi}}\left(\frac{Y_{t+1}}{Y_{t+1}^{N}}\right)^{\phi_{x}}\right]\left(\frac{\theta_{t}}{\bar{\theta}}\right)^{\frac{-\phi_{\mu}}{\bar{\theta}-1}} \xi_{t}^{\phi_{\varphi}} \varrho_{t}
$$

where $\phi_{\pi}>0$, and $\phi_{\varphi}$ and $\phi_{\mu}$ are unrestricted, $R$ and $\bar{\theta}$ are the steady state values of $R_{t}$ and $\theta_{t}, \varrho_{t}$ is a monetary policy shock that, in logarithm, follows a stationary process with mean zero, and $y_{t}^{n}$ is the natural level of output. The latter is defined as the level of output that equals the marginal cost to the inverse of the steady state mark-up level. We choose this monetary policy rule to maintain comparability with Carvalho et al. (2017), and to capture the behavior of a central bank that reacts to expected inflation and output gap, as well as to mark-up and demand shocks.

\section{2}

\section{Rational Expectations}

Before solving the model under subjective beliefs, as is standard in the learning literature, one must find the rational expectations equilibrium upon which agents base their statistical model. To that matter, we follow the essentially affine method proposed in Dew-Becker (2012) to log-linearize the model around the non-stochastic steady state with zero inflation. In a nutshell, the idea is to separate the model into expectational and non-expectational

${ }^{4}$ Notice that we already use the fact that, in equilibrium, markets must clear, that is, $Y_{t}(f)=C_{t}(f)$. 
equations and, then, to log-linearize the first group in the usual way and the second group considering log-normality properties.

The first step is to conjecture that the solution takes the form of

$$
\hat{X}_{t+1}=C+\Phi \hat{X}_{t}+\Psi \varepsilon_{t},
$$

where $\hat{X}_{t}$ is the vector of state variables in log-deviations from the nonstochastic steady state, and $\varepsilon_{t}$ is a vector of structural innovations, both to be later defined. Henceforth, we use $\Gamma_{z}$ as the selector vector of variable $z$ in $\hat{X}_{t}$, and $e_{z}$ as the selector vector of innovation $z$ in $\varepsilon_{t}$. It needs to be emphasized that there is no analytic solution to the problem, for the solution depends on a unknown matrix, $\Psi$, of error loadings. Therefore, to solve the system, the Gensys algorithm should be used to perform iterations until convergence. The first iteration must disconsider second order effects, with $\sigma$ set to zero. In the following iterations, $\sigma$ should be set to one.

From the Euler equation for the utility portfolio, one may find an approximation for the stochastic discount factor (SDF). Henceforth, for any variable $Z_{t}, \hat{z}_{t} \equiv \ln \left(\frac{X_{t}}{\bar{X}}\right)$, and $\tilde{\varphi}_{t} \equiv \ln \left(\xi_{t}\right)$. The approximation to the $\mathrm{SDF}$ is then

$$
\begin{aligned}
\hat{m}_{t+1} & =\zeta_{t}\left(-\rho \Gamma_{y}+\Gamma_{r}+\Gamma_{\varphi}\right)\left(\hat{X}_{t+1}-\mathbb{E}_{t} \hat{X}_{t+1}\right) \\
& -\frac{1}{2} \sigma^{2} \zeta_{t}^{2}\left(-\rho \Gamma_{y}+\Gamma_{r}+\Gamma_{\varphi}\right) \Psi \Sigma \Psi^{\prime}\left(-\rho \Gamma_{y}+\Gamma_{r}+\Gamma_{\varphi}\right)^{\prime}-\Gamma_{r} \hat{X}_{t+1},
\end{aligned}
$$

where $\zeta_{t} \equiv \frac{1-\alpha_{t}}{1-\rho}, m_{t+1} \equiv \ln \left(\Lambda_{t+1} / \beta\right)$, and $\mathbb{E}_{t}$ is the rational expectations operator.

Moreover, it is necessary to find the expression for real marginal cost of firms, which is related to the natural level of output, to the optimal number of hours worked by each household, and to the inflation. To find the marginal cost function, we follow Woodford (2003), but assume a production function of the form $Y_{t}(f)=A_{t}\left(h_{t}(f)\right)^{1-\lambda}$ for all $f \in[0,1]$, where $A_{t}>0$ is a time-varying exogenous technology factor and $0<\lambda<1$. The following approximation for the marginal cost function may be shown to hold,

$$
\hat{s}_{t}=(\omega+\rho)\left(\hat{y}_{t}-\hat{y}_{t}^{n}\right)
$$

where $\omega$ is the elasticity of a firm's real marginal cost function with respect to its own output.

Additional equilibrium relations are given by the value function, and the return and the cum-sum dividend on the utility portfolio, as below 


$$
\begin{gathered}
\hat{V}_{t}=\left(\frac{1-\beta}{1-\rho}\right)\left(\omega_{y} \hat{y}_{t}+\omega_{n} \hat{y}_{t}^{n}+\tilde{\varphi}_{t}\right)+\beta \Gamma_{V} \mathbb{E}_{t} \hat{X}_{t+1}+(1-\alpha) \frac{\sigma_{G}^{2}}{2} \Gamma_{V} \Psi \Sigma \Psi^{\prime} \Gamma_{V}^{\prime} \\
\hat{r}_{U, t+1}=\hat{w}_{U, t+1}-\frac{1}{\beta} \hat{w}_{U, t}+\frac{1-\beta}{\beta}\left(\left(\omega_{y}+\rho\right) \hat{y}_{t}+\omega_{n} \hat{y}_{t}^{n}\right) \\
\hat{w}_{U, t+1}=(1-\rho) \hat{V}_{t+1}+\rho \hat{y}_{t+1}-\tilde{\varphi}_{t+1}
\end{gathered}
$$

where $\omega_{h}=\frac{U_{h} \bar{h}}{U}, \omega_{c}=\frac{U_{c} \bar{C}}{U}, \omega_{y}=\omega_{c}+\frac{\omega_{h}}{1-\lambda}, \omega_{n}=-\frac{\omega_{h}}{1-\lambda} \cdot \frac{(\omega+\rho)}{\chi}$, and $\chi$ is the elasticity of the real marginal cost function to technology, evaluated at the steady state.

Combining the Euler equation for the one period bond and the monetary policy rule, yields the relation that determines the aggregate demand of this economy, given by

$$
\begin{aligned}
& \left(\Gamma_{r}-\phi_{\pi} \Gamma_{\pi^{*}}-\phi_{x}\left(\Gamma_{y}-\Gamma_{y^{N}}\right)\right) \mathbb{E}_{t} \hat{X}_{t+1}=K_{i} \\
& \quad+\left(\phi_{\mu} \Gamma_{\mu}+\phi_{\varphi} \Gamma_{\varphi}+\frac{\sigma^{2}}{1-\rho}\left(-\rho \Gamma_{y}+\Gamma_{r}+\Gamma_{\varphi}\right) \Psi \Sigma \Psi^{\prime}\left(-\rho \Gamma_{y}+\Gamma_{r}+\Gamma_{\varphi}\right)^{\prime} \Gamma_{\alpha}\right) \hat{X}_{t}
\end{aligned}
$$

where $K_{i} \equiv K_{e u}+K_{t r}, K_{e u}=\sigma^{2}\left[\frac{1}{2}\left(\Gamma_{r}+\Gamma_{\pi}\right) \Psi \Sigma \Psi^{\prime}\left(\Gamma_{r}+\Gamma_{\pi}\right)^{\prime}-\bar{\zeta}\left(-\rho \Gamma_{y}+\Gamma_{r}+\right.\right.$ $\left.\left.\Gamma_{\pi}\right) \Psi \Sigma \Psi^{\prime}\left(\Gamma_{r}+\Gamma_{\pi}\right)^{\prime}\right]$, and $K_{t r} \equiv \frac{\sigma^{2}}{2}\left[\phi_{\pi} \Gamma_{\pi^{*}}+\Gamma_{\pi}+\phi_{x}\left(\Gamma_{y}-\Gamma_{y^{N}}\right)\right] \Psi \Sigma \Psi^{\prime}\left[\phi_{\pi} \Gamma_{\pi^{*}}+\right.$ $\left.\Gamma_{\pi}+\phi_{x}\left(\Gamma_{y}-\Gamma_{y^{N}}\right)\right]^{\prime}$.

Regarding the trajectory of inflation, the equilibrium relation that determines it comes from the first order condition of the firm's problem. A log-linear approximation to the latter yields

$$
\pi_{t}^{*}=\xi_{p}\left(\hat{s}_{t}+\tilde{\mu}_{t}\right)+\beta \mathbb{E}_{t} \pi_{t+1}^{*}+\Omega_{\pi}
$$

where $\pi_{t}^{*}=\pi_{t}-\gamma \pi_{t-1}, \Omega_{\pi} \equiv \frac{\sigma^{2}}{2} \frac{\beta^{2} \Phi_{s}}{\bar{Y}} \Gamma_{\pi^{*}} \Psi \Sigma \Psi^{\prime} \Gamma_{\pi^{*}}^{\prime}, \xi_{p}=\frac{(1-\alpha)(1-\beta \alpha)}{\alpha}$, and $\alpha$ is the model's stable eigenvalue. In addition, $\tilde{\mu}_{t}=-\hat{\theta}_{t} / \bar{\theta}$, represents mark-up shocks.

To close the model, the exogenous processes must be defined. Those are the processes the determine the relative coefficient of risk aversion of households, $\alpha_{t}$, monetary policy shocks, $\tilde{\varrho}_{t}$, mark-up shocks, $\tilde{\mu}$, demand shocks, $\tilde{\varphi}_{t}$, and technology shocks (the only source of shocks to the natural output), $\hat{y}_{t}^{n}$. We assume that these are all covariance stationary processes, defined as below: 


$$
\begin{aligned}
& \tilde{\varrho}_{t+1}=\rho_{\varrho} \tilde{\varrho}_{t}+\varepsilon_{t+1}^{\varrho}, \varepsilon_{t+1}^{\varrho} \sim N\left(0, \sigma_{\varrho}^{2}\right), \\
& \alpha_{t+1}=\left(1-\rho_{\alpha}\right) \bar{\alpha}+\rho_{\alpha} \alpha_{t}+\varepsilon_{t+1}^{\alpha}, \varepsilon_{t+1}^{\alpha} \sim N\left(0, \sigma_{\alpha}^{2}\right), \\
& \tilde{\varphi}_{t+1}=\rho_{\varphi} \tilde{\varphi}_{t}+\varepsilon_{t+1}^{\varphi}, \varepsilon_{t+1}^{\varphi} \sim N\left(0, \sigma_{\varphi}^{2}\right), \\
& \tilde{\mu}_{t+1}=\rho_{\mu} \tilde{\mu}_{t}+\varepsilon_{t+1}^{\mu}, \varepsilon_{t+1}^{\mu} \sim N\left(0, \sigma_{\mu}^{2}\right), \\
& \hat{y}_{t+1}^{n}=\rho_{y^{n}} \hat{y}_{t}^{n}+\varepsilon_{t+1}^{y^{n}}, \varepsilon_{t+1}^{y^{n}} \sim N\left(0, \sigma_{y^{n}}^{2}\right) .
\end{aligned}
$$

Additionally, we define the vectors $\hat{X}_{t}$ and $\varepsilon_{t}$ as

$$
\begin{gathered}
\hat{X}_{t} \equiv\left[\varrho_{t} \hat{\alpha}_{t} \tilde{\varphi}_{t} \tilde{\mu}_{t} \hat{y}_{t}^{n} \pi_{t} \hat{r}_{U, t} \hat{w}_{U, t} \hat{y}_{t} \hat{V}_{t} \pi_{t}^{*}\right]^{\prime} \\
\varepsilon_{t} \equiv\left[\begin{array}{lllll}
\varepsilon_{t}^{\varrho} & \varepsilon_{t}^{\alpha} & \varepsilon_{t}^{\varphi} & \varepsilon_{t}^{\mu} & \varepsilon_{t}^{y^{n}}
\end{array}\right]^{\prime} .
\end{gathered}
$$

\section{3}

\section{Subjective Beliefs}

In this section, we present the solution of the model under subjective beliefs. As already mentioned, we assume that the only uncertainty in this economy comes from the fact that agents do not know the long-run mean of inflation, interchangeably referred to as the inflation target or as trend inflation, and must estimate it from the data. The next subsection discusses the solution under subjective beliefs and presents the equations that determine the true data generating process under subjective beliefs, while the following subsection introduces the process by which the forecasts for this target are updated over time. In subsequent subsections, we address the implications of the model to the term structure of government bond yields. Importantly, this dissertation is not concerned with the impacts of heterogeneous beliefs, but, rather, with the effects of anchored or unanchored expectations on a general basis. Therefore, hereafter, the basic assumption is that of homogeneous beliefs, meaning that the solution is computed under a symmetric equilibrium.

\subsection{1}

\section{Solution under Subjective Beliefs}

As is standard in the learning literature, we assume that agents forecast state variables based on the perceived law of motion augmented by the long term inflation target forecast. The statistical model used for forecasting state variables is given by

$$
\hat{X}_{t+1}=C+\Phi \hat{X}_{t}+\Theta \bar{\pi}_{t+1}+u_{t+1}
$$


where $u_{t}$ denotes a vector of independent residuals satisfying $\hat{E}_{t} u_{t+1}=0, \bar{\pi}_{t}$ is the estimated long-run mean of inflation, and

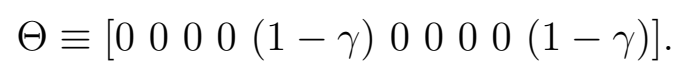

The vector $\Theta$ captures the idea that because agents do not know the longrun mean of inflation, they include a stochastic intercept in their forecasts for inflation. Note that the framework presented here represents only a small departure from rational expectations, and that agents know the law of motion of structural innovations such that log-normality properties may be used in the approximation of the model under subjective beliefs.

In addition, we assume, as in Carvalho et al. (2017), that beliefs about trend inflation satisfy

$$
\hat{E}_{t-1} \bar{\pi}_{T}=\bar{\pi}_{t}, \text { for all } T \geq t
$$

where $\hat{E}_{t-1} \bar{\pi}_{t}$ is the firm's one-period-ahead forecast (based on the statistical model above).

The non-expectational equations are not directly affected by the introduction of learning as they represent either identities that assist in writing the model recursively or the data generating process of exogenous variables. Thus, only the expectational equations must be addressed, namely the Taylor rule, the aggregate demand equation, the aggregate supply equation, and the evolution of the value function of households. Additionally, a crucial point to the derivation is that the forecast for the inflation target is predetermined in the sense that is based, solely, on the information from the last period (as discussed in the next subsection). In other words, the forecast $\bar{\pi}_{t+1}$ relies completely on information of period $t$. This assumption is quite usual in the learning literature and resolves a simultaneity problem (see Evans and Honkapohja, 2001; Eusepi and Preston, 2018; Milani, 2012, 2014). The main consequence is that there is no covariance between variables in $t+1$ and the inflation target forecast, $\bar{\pi}_{t+1}$, conditional on the information set of period $t$.

The derivation of the process that determines the evolution of the value function is not much affected by the introduction of learning, so that the resulting equation is similar to (2-10), but with subjective expectations in place of the mathematical expectation. The resulting process for the value function is

$$
M_{V}^{X} \hat{X}_{t}=M_{V}^{C}+M_{V}^{\pi} \bar{\pi}_{t}
$$


where

$$
\begin{gathered}
M_{V}^{C} \equiv \beta\left(\Gamma_{V} C+\frac{(1-\bar{\alpha})}{2} \Gamma_{V} \Psi \Sigma \Psi^{\prime} \Gamma_{V}^{\prime}\right) \\
M_{V}^{\pi} \equiv \beta \Gamma_{V} \Theta \\
M_{V}^{X} \equiv \Gamma_{V}(I-\beta \Phi)-\left(\frac{1-\beta}{1-\rho}\right)\left[\omega_{y} \Gamma_{y}+\omega_{N} \Gamma_{y^{N}}+\Gamma_{\varphi}\right]+\frac{\beta}{2} \Gamma_{V} \Psi \Sigma \Psi^{\prime} \Gamma_{V}^{\prime} \Gamma_{\alpha} .
\end{gathered}
$$

The second relation that is affected by the introduction of subjective beliefs is the price-setting problem faced by each of the firms. To find the solution, return to (2-5), and take a log-linear approximation to the first order condition of that problem. This procedure yields

$$
\begin{aligned}
p_{t}^{*}(f)=\alpha p_{t-1}^{*}(f)+\alpha \pi_{t}^{*}-\alpha \hat{E}_{t} \sum_{T=t}^{\infty}(\alpha \beta)^{T-t}\left[\xi_{p} \hat{s}_{T}+\beta(1-\alpha) \pi_{T+1}^{*}\right] & -\alpha \xi_{p} \tilde{\mu}_{t} \\
& -\frac{\alpha \beta^{2} \Phi}{2 \bar{Y}(1-\alpha \beta)} \Gamma_{\pi^{*}} \Psi \Sigma \Psi^{\prime} \Gamma_{\pi^{*}}^{\prime}
\end{aligned}
$$

where $p_{t}^{*}(f)=\log \left(P_{t}(f) / P_{t}\right), \xi_{p} \equiv \frac{(1-\alpha)(1-\beta \alpha)}{\alpha}$, and $\alpha$ is the model's stable eigenvalue. In a symmetrical equilibrium, all firms must choose the same optimal price, so that $p_{t}^{*}(f)=0$ and the expression above simplifies to

$$
\pi_{t}^{*}=\hat{E}_{t} \sum_{T=t}^{\infty}(\alpha \beta)^{T-t}\left[\xi_{p} \hat{s}_{T}+\beta(1-\alpha) \pi_{T+1}^{*}\right]+\alpha \xi_{p} \tilde{\mu}_{t}+\tilde{\Omega}_{\pi}
$$

where $\tilde{\Omega}_{\pi} \equiv \frac{1}{1-\alpha \beta} \Omega_{\pi}$. Finally, considering both the statistical model defined in (2-16), and the assumption that agents only have information up to $t-1$ when forming expectations about $\bar{\pi}_{T}, T>t$, the true data generating process for the inflation under subjective beliefs is given by

$$
M_{\pi^{*}}^{X} \hat{X}_{t}=M_{\pi^{*}}^{C}+M_{\pi^{*}}^{\pi} \bar{\pi}_{t},
$$

where

$$
M_{\pi^{*}}^{C} \equiv \tilde{\Omega}_{\pi}+\beta\left(\alpha \Gamma_{s}+(1-\alpha) \Gamma_{\pi^{*}}\right)(I-\Phi)^{-1}\left[(1-\alpha \beta)^{-1} I-(I-\alpha \beta \Phi)^{-1} \Phi\right] C,
$$




$$
\begin{gathered}
M_{\pi^{*}}^{\pi} \equiv \beta\left(\alpha \Gamma_{s}+(1-\alpha) \Gamma_{\pi^{*}}\right)(I-\Phi)^{-1}\left[(1-\alpha \beta)^{-1} I-(I-\alpha \beta \Phi)^{-1} \Phi\right] \Theta \\
M_{\pi^{*}}^{X} \equiv \Gamma_{\pi^{*}}-\xi_{p}\left(\Gamma_{s}+\Gamma_{\mu}\right)-\beta\left(\alpha \Gamma_{s}+(1-\alpha) \Gamma_{\pi^{*}}\right)(I-\alpha \beta \Phi)^{-1} \Phi
\end{gathered}
$$

and $\Gamma_{s} \equiv(\omega+\rho)\left(\Gamma_{y}-\Gamma_{y^{n}}\right)$ from $(2-9)$.

The last relation that needs to be determined under subjective beliefs is aggregate demand, which we opt to derive under the Euler's approach, that is, by directly approximating the Euler equation for the one-period bond. The motivation is threefold. First, with an endogenous learning regime, the infinitehorizon approach, addressed in Preston (2005) and Sinha (2016), yields an intractable problem. The main issue is that the unconditional distribution of the gain parameter is unknown and, thus, prevents one from using lognormality properties in the approximation. Second, the main criticism to the Euler's approach is weakened in the present context. The method is mostly criticized for it presumes households to be short-sighted: the Euler equation only addresses the impact of subjective beliefs on the one-period decision between consumption today or tomorrow. Alternatively, in a model without recursive preferences, the infinite-horizon approach considers agents to be longsighted, as, by linearizing the agent's lifetime budget constraint, the impact of subjective beliefs is considered on a multiperiod decision. ${ }^{5}$ However, in the present framework, households have recursive preferences so that their stochastic discount factor depends on the evolution of the value function, which, in turn takes into account their expected lifetime utility. Therefore, even under Euler's approach, recursive preferences induce agents to be, if not long-sighted in the sense of Preston (2005), at least medium-sighted, in that they consider the impact of subjective beliefs in more than just the one-period decision. Third, in the more simple framework in Carvalho et al. (2017), the solution for the model under the infinite-horizon approach and under Euler's approach coincides. ${ }^{6}$

Having in mind the discussion above, the first step to find the aggregate demand relation is to approximate both the Euler equation for the one-period bond and the monetary policy rule, considering log-normality properties and computing expectations under the statistical model in (2-16). Combining the

${ }^{5}$ See Preston (2005) for a discussion.

${ }^{6}$ The derivation of both solutions is available upon request. 
approximation of those two relations yields the true data generating process for the intended relation,

$$
M_{D A}^{X} \hat{X}_{t}=M_{D A}^{C}+M_{D A}^{\pi} \bar{\pi}_{t}
$$

where

$$
\begin{gathered}
M_{D A}^{X} \equiv\left[\Gamma_{r}-\phi_{\pi} \Gamma_{\pi^{*}}-\phi_{x}\left(\Gamma_{y}-\Gamma_{y^{N}}\right)\right] \Phi-\phi_{\mu} \Gamma_{\mu}-\phi_{\varphi} \Gamma_{\varphi}-\frac{1}{1-\rho}\left(-\rho \Gamma_{y}+\Gamma_{r}+\Gamma_{\varphi}\right) \Psi \Sigma \Psi^{\prime}\left(\Gamma_{r}+\Gamma_{\pi}\right)^{\prime} \Gamma_{\alpha} \\
M_{D A}^{C} \equiv K_{i}-\left[\Gamma_{r}-\phi_{\pi} \Gamma_{\pi^{*}}-\phi_{x}\left(\Gamma_{y}-\Gamma_{y^{N}}\right)\right] C \\
M_{D A}^{\pi} \equiv-\left[\Gamma_{r}-\phi_{\pi} \Gamma_{\pi^{*}}-\phi_{x}\left(\Gamma_{y}-\Gamma_{y^{N}}\right)\right] \Theta .
\end{gathered}
$$

Finally, the model may be summarized in state-space form. There are eleven variables that compose the state vector $\hat{X}_{t}$. The first five (that is, $\varrho_{t}, \hat{\alpha}_{t}, \tilde{\varphi}_{t}, \tilde{\mu}_{t}$, and $\left.\hat{y}_{t}^{n}\right)$ are exogenous, the following three $\left(\pi_{t}, \hat{r}_{U, t}\right.$, and $\left.\hat{w}_{U, t}\right)$ are determined directly by the identities included in the non-expectational equations, and solely the last three variables, namely, $\hat{y}_{t}, \hat{V}_{t}$, and $\pi_{t}^{*}$, depend on expectations. The true data generating process of those last three variables was just derived. Therefore the model may be written recursively as

$$
M_{X} \hat{X}_{t}=M_{C}+M_{X^{\prime}} \hat{X}_{t-1}+M_{\pi} \bar{\pi}_{t}+M_{\varepsilon} \varepsilon_{t},
$$

which, by inverting $M_{X}$, yields the true data generating process of $\hat{X}_{t}$,

$$
\hat{X}_{t}=\tilde{C}+\tilde{\Phi} \hat{X}_{t-1}+\tilde{\Theta} \bar{\pi}_{t}+\tilde{\Psi} \varepsilon_{t},
$$

where $\tilde{C}=M_{X}^{-1} M_{C}, \tilde{\Phi}=M_{X}^{-1} M_{X^{\prime}}, \tilde{\Theta}=M_{X}^{-1} M_{\pi}$, and $\tilde{\Psi}=M_{X}^{-1} M_{\varepsilon}$.

As would be expected, the process in (2-21) resembles the equilibrium under rational expectations, differing from it in two ways. First, it includes the estimated inflation target as state variable. Second, the values in $\tilde{C}, \tilde{\Phi}$, and $\tilde{\Psi}$, may not equal those in (2-7).

\subsection{2}

\section{Expectation Formation Process}

Given that the objective of this dissertation is to address the implications of the anchoring of inflation expectations to the term structure of bond yields, the process that determines the evolution of agents' forecasts for the inflation target is crucial to the results. We choose to use the same process put forward 
in Carvalho et al. (2017) for two main reasons. First, it captures the idea that expectations regarding the long-run mean of inflation should evolve differently based on whether they are anchored or not. Second, the authors are successful in the estimation and out-of-sample fit of a simpler New-Keynesian model with this learning algorithm. ${ }^{7}$

Beliefs about trend inflation are revised according to an algorithm linking the current estimate to the last prediction error

$$
\begin{gathered}
\bar{\pi}_{t}=\bar{\pi}_{t-1}+k_{t}^{-1} f_{t-1} \\
f_{t}=\pi_{t}-\hat{E}_{t-1} \pi_{t}=\Gamma_{\pi}(\tilde{C}-C)+\Gamma_{\pi}(\tilde{\Phi}-\Phi) \hat{X}_{t-1}+\Gamma_{\pi}(\tilde{\Theta}-\Theta) \bar{\pi}_{t}+\eta_{t}, \\
k_{t+1}=\left\{\begin{array}{r}
k_{t}+1 \\
\bar{g}^{-1}
\end{array} \text { otherwise } \quad\left|\hat{E}_{t-1} \pi_{t}-E_{t-1} \pi_{t}\right| \leq \nu \sigma^{\eta}\right.
\end{gathered}
$$

where $\eta_{t} \equiv \Gamma_{\pi} \tilde{\Psi} \varepsilon_{t} ; \nu \geq 0$ and $g>0$ are parameters; $\sigma^{\eta} \equiv\left(\Gamma_{\pi} \tilde{\Psi} \Sigma \tilde{\Psi}^{\prime} \Gamma_{\pi}^{\prime}\right)^{\frac{1}{2}}$ is the standard-deviation of variable $\eta_{t}{ }^{8} \hat{E}_{t-1} \pi_{t}$ is the firm's one-period-ahead forecast; and $E_{t-1} \pi_{t}$ is the model-consistent one-period-ahead expectation. When $\nu>0$, the algorithm is characterized by an endogenous switch between constant gain and decreasing gain learning that allows agents to track monetary policy regime changes.

The state-dependent gain $k_{t}$ safeguards against structural change, as emphasized in Carvalho et al. (2017). When constant-gain learning is employed, better forecasts are produced in response to changing economic environment, with decreasing weight to older observations. Alternatively, decreasing-gain estimator, that corresponds to the usual recursive least-squares solution, performs better in an environment with time-invariant mean.

Notice that the above algorithm relies on the implicit assumption that only information up to period $t-1$ is available to agents when forming their period $t$ expectations about the inflation target. ${ }^{9}$ Notice, further, that assumption (2-17) characterizes a shifting endpoint model, as in Kozicki and Tinsley (2001), and implies that agents do not account for future revisions in

${ }^{7}$ Their model does not account for time-varying risk premia, nor addresses the term structure of interest rates.

${ }^{8}$ For simplicity, we estimated the model considering $\sigma^{\eta}=\sigma^{\varrho}+\sigma^{\alpha}+\sigma^{\varphi}+\sigma^{\mu}+\sigma^{y n}$. This does not qualitatively affect results, as the constant $\nu$ will adjust to changes in $\tilde{\sigma}$.

${ }^{9}$ This is a rather common assumption in learning literature as it resolves a complicated simultaneity. See Milani (2012), Milani (2014), Eusepi and Preston (2018) and Evans and Honkapohja (2001). 
their estimates of the inflation target when making period $t$ decisions. ${ }^{10}$

\subsection{3}

\section{Term Structure}

To find the parameters that define the term structure of interest rates, one must return to the first order conditions of the household's problem. The Euler equation for a zero-coupon bond of maturity $\tau$ is

$$
P_{\tau, t}^{B}=\hat{E}_{t}\left[\frac{\Lambda_{t+1}}{\Pi_{t+1}} P_{\tau-1, t+1}^{B}\right] .
$$

Approximate (2-25) with the essentially affine method and conjecture that bond prices, in logarithm, are an affine function of the state variables, that is,

$$
p_{\tau, t}^{B}=A_{\tau}+B_{\tau} \hat{X}_{t}+C_{\tau} \bar{\pi}_{t}
$$

to find a recursion on parameters $A_{\tau}, B_{\tau}$, and $C_{\tau}$. From the Euler equation for the one-period bond, the initial parameters $A_{1}, B_{1}$, and $C_{1}$ may be determined, because $i_{t} \approx-p_{1, t}^{B}$, where $i_{t} \equiv \log \left(R_{t} / \bar{R}\right)$ is the interest rate set by the monetary authority. ${ }^{11}$ For $\tau>1$, bond prices depend on the following parameters:

$$
\begin{gathered}
A_{\tau}=A_{\tau-1}-\bar{r}+\frac{1}{2}\left(B_{\tau-1}-\Gamma_{\pi}-\Gamma_{r}\right) \Psi \Sigma \Psi^{\prime}\left(B_{\tau-1}-\Gamma_{\pi}-\Gamma_{r}\right)^{\prime} \\
+\bar{\zeta}\left(B_{\tau-1}-\Gamma_{\pi}-\Gamma_{r}\right) \Psi \Sigma \Psi^{\prime}\left(-\rho \Gamma_{y}+\Gamma_{r}+\Gamma_{\varphi}\right)^{\prime}+\left(B_{\tau-1}-\Gamma_{\pi}-\Gamma_{r}\right) C, \\
B_{\tau}=\left(B_{\tau-1}-\Gamma_{\pi}-\Gamma_{r}\right) \Phi-\frac{1}{1-\rho}\left(B_{\tau-1}-\Gamma_{\pi}-\Gamma_{r}\right) \Psi \Sigma \Psi^{\prime}\left(-\rho \Gamma_{y}+\Gamma_{r}+\Gamma_{\varphi}\right)^{\prime} \Gamma_{\alpha}, \\
C_{\tau}=C_{\tau-1}+\left(B_{\tau-1}-\Gamma_{\pi}-\Gamma_{r}\right) \Theta .
\end{gathered}
$$

${ }^{10}$ This is an example of the anticipated utility approach, as discussed in Eusepi and Preston (2018) and Kreps (1998).

${ }^{11}$ For $\tau=1$,

$$
\begin{gathered}
A_{1}=\frac{1}{2}\left(\Gamma_{r}+\Gamma_{\pi}\right) \Psi \Sigma \Psi^{\prime}\left(\Gamma_{r}+\Gamma_{\pi}\right)^{\prime}-\bar{r}-\left(\Gamma_{r}+\Gamma_{\pi}\right) C-\bar{\zeta}\left(-\rho \Gamma_{y}+\Gamma_{r}+\Gamma_{\varphi}\right) \Psi \Sigma \Psi^{\prime}\left(\Gamma_{r}+\Gamma_{\pi}\right)^{\prime}, \\
B_{1}=\frac{1}{1-\rho}\left(-\rho \Gamma_{y}+\Gamma_{r}+\Gamma_{\varphi}\right) \Psi \Sigma \Psi^{\prime}\left(\Gamma_{r}+\Gamma_{\pi}\right)^{\prime} \Gamma_{\alpha}-\left(\Gamma_{r}+\Gamma_{\pi}\right) \Phi, \\
C_{1}=\gamma-1 .
\end{gathered}
$$


From the term structure of bond prices, the term structure of interest rates is determined. Indeed, the continuously compounded yield of a $\tau$-period zero coupon bond, $r_{\tau, t}^{B}$, is simply $r_{\tau, t}^{B}=-\frac{p_{\tau, t}^{B}}{\tau}$. Notice, additionally, that to obtain the term structure under rational expectations it suffices to set $\bar{\pi}_{t}=0$. The yield on a $\tau$-period bond may be shown to follow

$$
r_{\tau, t}=\left[(1-\gamma)-\frac{1}{\tau}\left(\sum_{i=1}^{\tau-1} B_{i}\right) \Theta\right] \bar{\pi}_{t}-\frac{1}{\tau}\left(A_{\tau}+B_{\tau} \hat{X}_{t}\right) .
$$

What is particularly interesting about that expression is that the term structure of bond yields is state-dependent in the sense that it depends on the evolution of the estimated inflation target, which, in turn, evolves differently depending on the state of the economy. To see that this last statement is true, return to (2-24) and observe that

$$
\hat{E}_{t-1} \pi_{t}-E_{t-1} \pi_{t}=\Gamma_{\pi}(\tilde{C}-C)+\Gamma_{\pi}(\tilde{\Phi}-\Phi) \hat{X}_{t-1}+\Gamma_{\pi}(\tilde{\Theta}-\Theta) \bar{\pi}_{t}
$$

This expression highlights the fact that agents only switch learning regimes when they experience large forecast errors. Although other factors may affect the size of the difference in (2-27), expectations tend to become unanchored whenever the absolute value of the long-run mean of inflation estimated by agents is large enough. This important intuition can be further understood from equation (2-22). Rewriting it as

$$
\bar{\pi}_{t}=\bar{\pi}_{0}+\sum_{i=1}^{t-1} k_{i} f_{i}
$$

points that the inflation target forecast in period $t$ is determined by a weighted sum of past forecast errors. The estimated trend inflation tends to be large when forecast errors happen to be of the same sign for several periods. Therefore, the occurrence of large and persistent shocks, implying large forecast errors, should actually trigger the unanchoring of expectations. Whereas in a stable macroeconomic scenario, in which the difference between subjective and model-consistent expectations tends to be small, inflation expectations should be anchored.

The last variable to be addressed is the term premium. The term premium on a $\tau$-period bond, $t p_{\tau, t}$, is defined as the difference between the yield on that bond and the expected return on rolling $\tau-1$ one-period bonds (that is, the yield on the $\tau$-period bond that would prevail under the Expectations Hypothesis), and may be shown to follow the process 


$$
\begin{aligned}
t p_{t, \tau}= & \left\{B_{1}(I-\Phi)^{-1}\left[I-\frac{1}{\tau}(I-\Phi)^{-1}\left(I-\Phi^{\tau}\right)\right]-\frac{1}{\tau}\left(\sum_{i=1}^{\tau-1} B_{i}\right)\right\} \Theta \bar{\pi}_{t} \\
& +\frac{1}{\tau}\left[B_{1}(I-\Phi)^{-1}\left(I-\Phi^{\tau}\right)-B_{\tau}\right] \hat{X}_{t} \\
& +\left\{A_{1}-\frac{1}{\tau} A_{\tau}+B_{1}(I-\Phi)^{-1}\left[I-\frac{1}{\tau}(I-\Phi)^{-1}\left(I-\Phi^{\tau}\right)\right] C\right\} .
\end{aligned}
$$

Numerical results show that the term multiplying $\bar{\pi}_{t}$ in equation (2-29) is zero. The reason for that is that the estimated inflation target for period $t+1$, which is predetermined, does not covary with the state variables in $t+1$ and, therefore, with the variables that compose the stochastic discount factor of agents, $\Gamma_{t+1}$. However, because inflation expectations being anchored or not affects the way in which state variables evolve over time, the variability of the term premium changes depending on the state of the economy. This can be seen from Figures B.1 and B.2, in Appendix B. The first presents the simulated moments of the term premium for different maturities in the different states of the economy, while the second one presents the impulse response functions for the term premia. Both exercises are based on the estimated version of the model (discussed in the next chapter). 


\section{Estimation}

This chapter discusses and assesses the results of the estimation of the model. The latter was estimated by Simulated Maximum Likelihood (SML) with data on short-run inflation expectations, inflation, consumption, and the term structure of government bond yields. The likelihood was evaluated based on the marginalized particle filter, ${ }^{1}$ which in turn was selected due to being computationally less expensive than the usual particle filter. A disadvantage of such choice, however, derives from the fact that our model is not conditionally linear and only an approximate version can be estimated. ${ }^{2}$

\section{1}

\section{The Approximate Model}

As aforementioned, to estimate the model in a more computationally efficient way, we made use of the marginalized particle filter, as employed in Carvalho et al. (2017), instead of the usual particle filter. However, because the solution to the model here presented is numerical, it is not possible to simplify the latter up to the point where one is sure that the model is conditionally linear as in Carvalho et al. (2017). To see why, notice from (2-24) that agents switch to constant gain learning regime only when

$$
\left|\hat{E}_{t-1} \pi_{t}-E_{t-1} \pi_{t}\right|>\nu \sigma^{\eta}
$$

but

$$
\hat{E}_{t-1} \pi_{t}-E_{t-1} \pi_{t}=\Gamma_{\pi}(\tilde{C}-C)+\Gamma_{\pi}(\tilde{\Phi}-\Phi) \hat{X}_{t-1}+\Gamma_{\pi}(\tilde{\Theta}-\Theta) \bar{\pi}_{t}
$$

meaning that $k_{t}$ is a function of both $\hat{X}_{t-1}$ and $\bar{\pi}_{t}$, and that the model is not conditionally linear unless $\Gamma_{\pi}(\tilde{\Phi}-\Phi)=0$.

In fact, depending on the calibration, this quantity may be either significantly large or practically null. To decide whether the approximate model

${ }^{1}$ See Lindstein and Schön (2013).

${ }^{2} \mathrm{An}$ important disclaimer at this point is that we are also conducting some Bayesian and SML estimations with longer data bases at the moment, but results were not available on time. 
is close enough to the true one, in the sense that simulated data under both models is similar, we impose the following limits:

$$
\Gamma_{\pi}(\tilde{\Phi}-\Phi) \Gamma_{e r}^{\prime} \leq\left\{\begin{array}{cc}
0.16 & \text { if } e r=\varrho, \\
0.10 & \text { if } e r \in\left\{\alpha, \varphi, \mu, y_{n}\right\}
\end{array}\right.
$$

Those limits were defined based on simulations and allow for mean squared error larger than two standard-deviations.

Assuming, then, the validity of the approximate model (i.e., setting $\Gamma_{\pi}(\tilde{\Phi}-\Phi)$ to zero), we are able to rewrite the model in state-space form as

$$
\begin{aligned}
& k_{t}=f_{k}\left(\bar{\pi}_{t-1}, k_{t-1}\right) \\
& \bar{\pi}_{t}=c_{\bar{\pi}}\left(\bar{\pi}_{t-1}, k_{t-1}\right)+a_{\bar{\pi}}\left(\bar{\pi}_{t-1}, k_{t-1}\right) \xi_{t-1} \\
& \xi_{t}=c_{\xi}\left(\bar{\pi}_{t-1}, k_{t-1}\right)+a_{\xi}\left(\bar{\pi}_{t-1}, k_{t-1}\right) \xi_{t-1}+S_{\xi} \varepsilon_{t}
\end{aligned}
$$

where the functions $f(\cdot), c(\cdot)$, and $a(\cdot)$ are defined in Appendix $\mathrm{B}, \xi_{t} \equiv$ $\left[\Gamma_{\pi} \Psi \varepsilon_{t}, \hat{X}_{t,-\mu}^{\prime}\right]^{\prime}$, and $\hat{X}_{t,-z}$ represents the vector $\hat{X}_{t}$ without the row relative to variable $z$.

\section{2}

\section{Data and Calibrated Parameters}

We estimate the model using quarterly data on inflation, short-term inflation expectations, real consumption, and the term structure of government bond yields. We also attach observation errors to all these series, which gives us the following measurement equation

$$
Y_{t}=h_{0, t}+h_{\pi, t} \bar{\pi}_{t}+H_{t}^{\prime} \xi_{t}+R_{t}^{\frac{1}{2}} e_{t}^{o}
$$

where $Y_{t}$ is the vector containing the observed data in period $t, h_{0, t}$ is a vector of constants, and $e_{t}^{o}$ is the vector of observation errors. The subscript $t$ in $h_{0, t}$, $h_{\pi, t}, H_{t}$, and $R_{t}$ controls for missing observations. Although the definition of the variables, vectors, and matrices in equation (3-3) can be found in Appendix $\mathrm{B}$, it is worth noticing that the vector $h_{0, t}$ includes the constant $\pi^{*}$, which represents the mean inflation rate in the data.

Following Dew-Becker (2014), because there is evidence for breaks in monetary policy prior to 1983, our sample spans from Q1.1983 to Q3.2018. Table 3.1 summarizes the data used in the estimation and their respective sources. 
Table 3.1: Data and Sources

\begin{tabular}{|c|c|c|}
\hline Model Variable & Source & Series \\
\hline$\hat{y}_{t}$ & $\begin{array}{l}\text { U.S. Bureau of Eco- } \\
\text { nomic Analysis }\end{array}$ & $\begin{array}{l}\text { Real per capita consumption } \\
\text { (nondurables and services), s.a., } \\
\text { logarithm was detrended with } \\
\text { one-sided HP-filter }\end{array}$ \\
\hline$\pi_{t}$ & $\begin{array}{l}\text { U.S. Bureau of La- } \\
\text { bor Statistics }\end{array}$ & log-differences, CPI, s.a. \\
\hline Infl. Expectations & $\begin{array}{l}\text { Survey of Profes- } \\
\text { sional Forecasters }\end{array}$ & 1- and 2-quarters ahead \\
\hline Infl. Expectations & Livingston Survey & $\begin{array}{l}\text { 1-semester ahead (two measures: } \\
\text { one available since the begin- } \\
\text { ning of the sample, and the other } \\
\text { starting at Q2.1992) }\end{array}$ \\
\hline Yield Curve & $\begin{array}{l}\text { Gürkaynak, Sack, } \\
\text { and Wright }(2007) \\
\text { - Gürkaynak et al. } \\
\text { (2007b) }\end{array}$ & 1-, 2-, 3-, 5-, 10-years bonds \\
\hline One-Period Interest Rate & $\begin{array}{l}\text { Board of Governors } \\
\text { of the Federal Re- } \\
\text { serve System (US) }\end{array}$ & (Effective) Fed Funds Rate \\
\hline
\end{tabular}

Regarding the term structure data, we choose to discard those observations on bonds for which the specific yields are constrained at the zero lower bound (ZLB). This means that, for some periods, the model is estimated only with data on inflation, inflation expectations, consumption, and unconstrained bond yields (for instance, yields on the 5- and the 10-year bonds are never constrained in our sample). We follow Swanson and Williams (2014) to determine the initial periods for which the observations on different bonds should be discarded, and consider the yields no longer constrained when they reach pre-ZLB levels. Table 3.2 summarizes yield specific dates.

We also choose to calibrate model parameters that represent steady-state (SS) values or that are expected to be harder to estimate from the data. We follow Dew-Becker (2014) and set the SS value of the labor's share of income and the Frisch elasticity to respectively $2 / 3$ and 1 . We also follow Christiano et al. (2014) with the SS value of the markup set to 1.2. The SS values of real wages, hours worked, and real consumption are chosen to match per capita data, while the rate of time preference is chosen to yield a real rate of $4.6 \%$. 
Table 3.2: Zero Lower Bound, periods

\begin{tabular}{ccc}
\hline Series & Start Date & End Date \\
\hline \hline Fed Funds & Q1.2003 & Q4.2004 \\
Fed Funds & Q1.2009 & Q4.2015 \\
Yield, 1-year bond & Q1.2010 & Q2.2015 \\
Yield, 2-year bond & Q3.2011 & Q1.2014 \\
Yield, 3-year bond & Q3.2012 & Q2.2013 \\
Yield, 5-year bond & - & - \\
Yield, 10-year bond & - & - \\
\hline
\end{tabular}

Table 3.3: Calibrated Parameters

\begin{tabular}{ccc}
\hline Parameter & Description & Value \\
\hline \hline $1-\lambda$ & SS, Labor's share of income & $2 / 3$ \\
$\bar{W} / \bar{P}$ & SS, real wages per capita & 78.212 \\
$\bar{h}$ & SS, hours worked per capita & 1,800 \\
$H$ & max. hours per capita, quarter & 8,760 \\
$\bar{Y}$ & SS, consumption per capita & 21,704 \\
$\bar{\theta} /(\bar{\theta}-1)$ & SS, markup & 1.2 \\
$\rho_{\mu}$ & AR $(1)$, markup shock & 0.000 \\
$\beta$ & rate of time preference & 0.956 \\
$\epsilon$ & Frisch elasticity & 1.000 \\
\hline \multicolumn{3}{c}{}
\end{tabular}

Calibration is summarized in Table 3.3.

\section{3}

\section{Estimated Parameters}

Table 3.4 contains the estimates of SML. To find the point of maximum, the likelihood was evaluated with the marginalized particle filter, considering 2,500 particles, and the optimization routine was initiated from 45 different points in the parameter space. First, ten random points were generated and used as initial condition of the optimization routine. The latter was based on a maximum of twelve rounds of different optimization algorithms, each with a limit of 1, 200 iterations. ${ }^{3}$ From these initial optimizations, the point associated with the highest likelihood was selected and used to produce five new random initial conditions to the optimization routine. This procedure was repeated until the optimization algorithm found a maximum and at least thirty points had been tested.

Some comments are due regarding the estimated parameters. First, and

${ }^{3}$ The optimization routine employs all of the following MATLAB algorithms to find the minimum: fminsearch, fminunc, and csminwel. 
Table 3.4: Estimated Parameters

\begin{tabular}{|c|c|c|}
\hline Parameter & Description & Value \\
\hline$\pi^{*}$ & constant, measurement equation & 13.680 \\
\hline$\rho$ & inverse EIS & 1.197 \\
\hline$\phi_{\pi}$ & reaction to inflation $(\mathrm{CB})$ & 0.995 \\
\hline$\phi_{x}$ & reaction to product gap (CB) & 0.409 \\
\hline$\phi_{\phi}$ & reaction to preference shock (CB) & 2.063 \\
\hline$\phi_{\mu}$ & reaction to markup shock (CB) & 4.975 \\
\hline$\gamma$ & inflation indexation & 0.501 \\
\hline$\rho_{\varrho}$ & AR(1), monetary policy shock & 0.511 \\
\hline$\rho_{\alpha}$ & $\mathrm{AR}(1)$, risk aversion shock & 0.886 \\
\hline$\rho_{\phi}$ & AR(1), preference shock & 0.527 \\
\hline$\rho_{y n}$ & $\mathrm{AR}(1)$, natural output shock & 0.197 \\
\hline $\bar{\alpha}$ & $\mathrm{SS}$, risk aversion & 7.490 \\
\hline$\delta$ & (equivalent to) Calvo parameter & 0.407 \\
\hline$\nu$ & threshold, learning algorithm & 0.008 \\
\hline $\bar{g}$ & constant gain learning parameter & 0.267 \\
\hline$\sigma_{\varrho}$ & std, monetary policy shock & 0.005 \\
\hline$\sigma_{\alpha}$ & std, risk aversion shock & 1.530 \\
\hline$\sigma_{\phi}$ & std, preference shock & 0.007 \\
\hline$\sigma_{\mu}$ & std, markup shock & 0.005 \\
\hline$\sigma_{y n}$ & std, natural output shock & 0.003 \\
\hline$\sigma_{\text {infl }}$ & std, observation shock & 0.010 \\
\hline$\sigma_{l i v 1}$ & std, observation shock & 0.001 \\
\hline$\sigma_{l i v 2}$ & std, observation shock & $1.94 \mathrm{E}-04$ \\
\hline$\sigma_{s p f 1 q}$ & std, observation shock & 0.001 \\
\hline$\sigma_{s p f 2 q}$ & std, observation shock & $1.37 \mathrm{E}-04$ \\
\hline$\sigma_{\text {cons }}$ & std, observation shock & 0.006 \\
\hline$\sigma_{f f}$ & std, observation shock & $4.00 \mathrm{E}-03$ \\
\hline$\sigma_{y 1 y}$ & std, observation shock & $9.00 \mathrm{E}-05$ \\
\hline$\sigma_{y 2 y}$ & std, observation shock & $1.54 \mathrm{E}-04$ \\
\hline$\sigma_{y 3 y}$ & std, observation shock & $1.01 \mathrm{E}-04$ \\
\hline$\sigma_{y 5 y}$ & std, observation shock & $2.83 \mathrm{E}-04$ \\
\hline$\sigma_{y 10 y}$ & std, observation shock & 0.001 \\
\hline
\end{tabular}


although the fit of the model to the data is good in general, the constant that should represent the mean of the inflation in the data, $\pi^{*}$, is estimated in 13.680, which is clearly at odds with the data. Second, the inverse EIS, $\rho$, and the model's stable eigenvalue (which is equivalent to the Calvo parameter), $\delta$, are estimated to be lower than the values calibrated in Dew-Becker (2014) (respectively, of 1.75 and 0.60). Additionally, the mean risk aversion is also lower than that estimated in Dew-Becker (2014): 7.49 here against a 90\% confidence interval of $[22.30,24.71]$ in the latter. Finally, the estimated ratio between the standard-deviation of the risk aversion shock and the mean risk aversion, of 0.20, is also slightly lower than that found in Dew-Becker (2014), with a $90 \%$ confidence interval of $[0.32,0.36]$.

Our results also differ from those of Carvalho et al. (2017). In particular, the estimated value for the learning gain parameter in Table 3.4, of 0.27 , is out of the $90 \%$ confidence interval in the paper, of $[0.10,0.20]$, and the same is true for the inflation indexation coefficient, of 0.50) against a $90 \%$ confidence interval of $[0.09,0.17]$.

Regarding the quality of the results here obtained, two main points should be highlighted. First, the point estimates in Table 3.4 are associated with a "very good" approximate model. Indeed, the measures given by $\Gamma_{\pi}(\tilde{\Phi}-$ $\Phi) \Gamma_{e r}^{\prime}$, with $e r \in\left\{\varrho, \alpha, \varphi, \mu, y_{n}\right\}$, are well bellow the limits imposed in (3-1): the sum of the absolute values of these measures equals only 0.03. Second, tests point that the structural parameters are identifiable from the data at the point in Table 3.4, although the Hessian matrix cannot be computed at this same point. The tests we ran follow Iskrev (2010), but, because our model can only be solved numerically and is unconditionally non-linear, some adaptation was due.

One of the tests proposed by Iskrev (2010) looks to how the SS values produced in a model change in response to marginal changes in the value of structural parameters. The column rank of the jacobian of those steady-state values with respect to structural parameters should indicate how many and exactly which of those parameters are identifiable. ${ }^{4}$ In our case, we have 19 structural parameters out of which 17 are identifiable from these SS values. As would be expected, the parameters that do not pass the test are those associated with the learning algorithm (that is, the threshold $\nu$ and the gain parameter $\bar{g}$ ), as they do not affect the SS of the model. A second test proposed by Iskrev (2010) evaluates the jacobian of the moments of the data generated by the model relative to the parameters of interest. Because of the non-linearity

\footnotetext{
${ }^{4}$ There are two possibilities when it comes to realizing which are the non-identifiable parameters: either the column associated to a parameter is null or there are two linearly dependent columns in the jacobian matrix, in which case both parameters are not identified.
} 


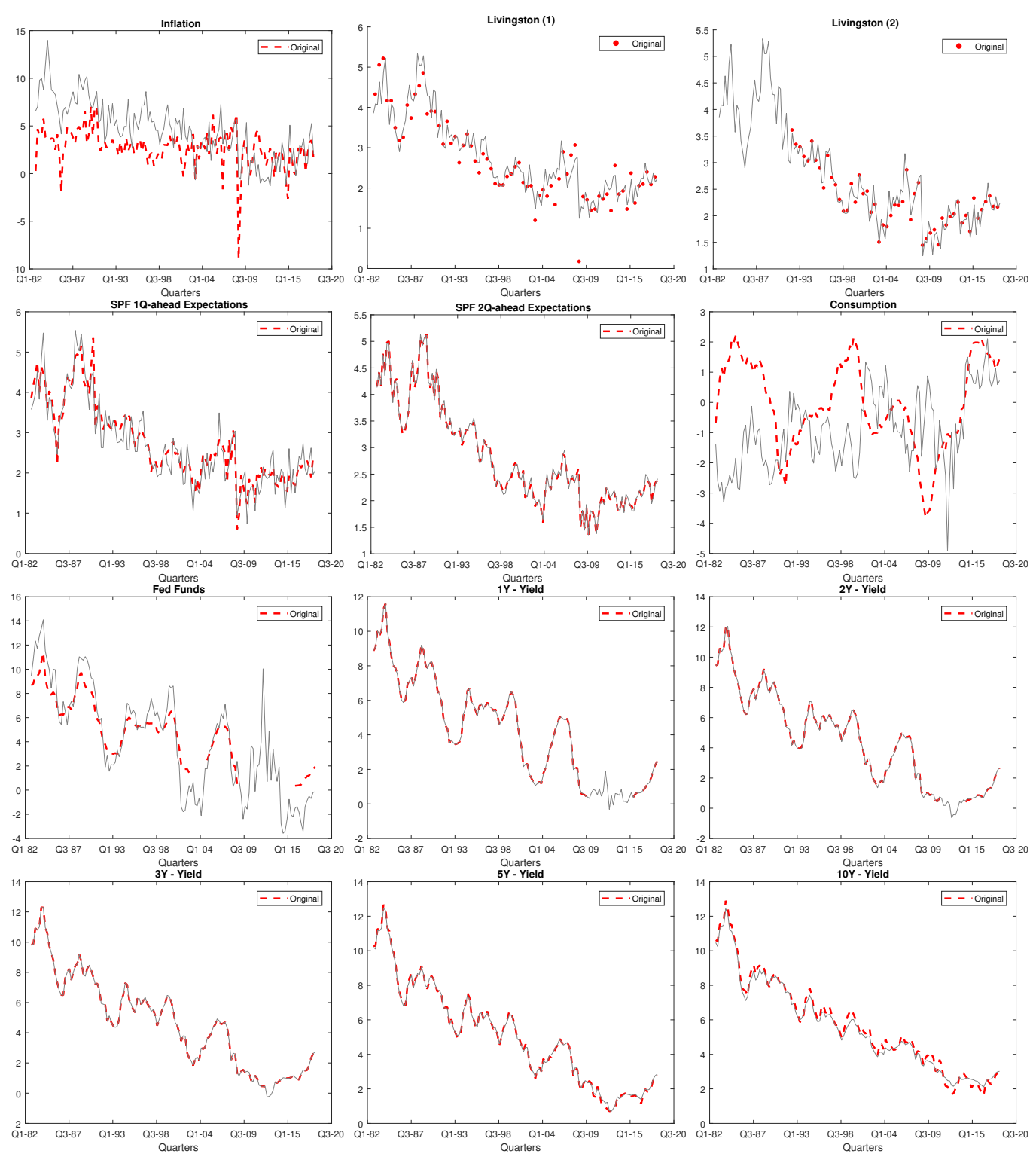

Figure 3.1: Fit of the Model to Observed Data

of our model, these unconditional moments cannot be computed analytically, so we rely on simulations. Those were based on 1,000 simulations of 1,000 periods each, and yielded a jacobian matrix with full column rank.

To further help in assessing the quality of our results, Figure 3.1 shows the original data used in the estimation, in red, plotted against the model's smoothed prediction, in grey. Such prediction was obtained using the marginalized particle smoother, as in Carvalho et al. (2017). Generally, the estimated model fits well the data on the term structure and on inflation expectations, nevertheless it cannot completely reproduce the behavior of inflation and of the short-rate (the fed funds rate), and, more importantly, it completely fails to reproduce the behavior of filtered consumption in the absence of relatively 
large observation errors. ${ }^{5}$ Regarding the properties of the filtered shocks in the estimated model, there is an overall significant autocorrelation, aside from larger variance of risk aversion shocks. Monetary policy shocks show the lowest variance across the five exogenous shocks that hit our theoretical economy. Figure B.3 in the Appendix B presents these shocks.

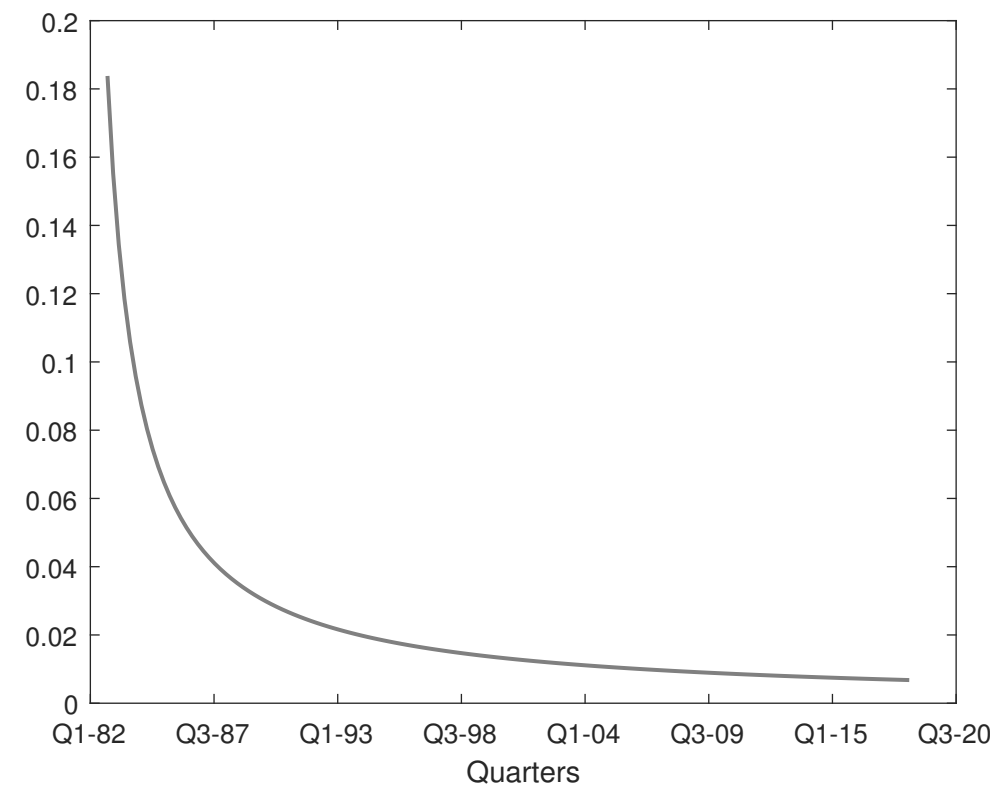

Figure 3.2: Learning Gain

Finally, as shown in Figure 3.2, the estimation implies that expectations were anchored all the way from 1983 through 2018. This conflicts with the results in Carvalho et al. (2017) that expectations were unanchored from 1975 up to 1995. A possible reason for our results is that our sample begins in 1983 so that, having left out data from the 1970's, the estimation did not have enough information to really find a parametrization that accounts for switches in the degree to which expectations are anchored. To address this matter, one could simply extend the time-span of the sample used in the estimation to at least 1970. Our suggestion, however, would be to employ a two-step estimation approach. In the first step, a simpler model model, which does not account for second-order effects, would be estimated with the same data sample used in Carvalho et al. (2017): that is, with data on inflation and short-term inflation expectations, starting in 1950. In the second step, the more complex model proposed in this dissertation would be estimated conditional on 1st-step estimates for structural parameters and with an extended sample containing data on the term structure and on consumption as well.

\footnotetext{
${ }^{5}$ Indeed, notice from Table 3.4 that the standard-deviation estimated for the consumption observation shock is the second largest among all observation errors.
} 


\section{4}

\section{State-Dependent Sensitivity of the Term Structure}

This chapter presents results from impulse-response functions and simulations. In all exercises, one-year forward rates are constructed by considering rates for groups of four periods, as the model was estimated with quarterly data. ${ }^{1}$ The purpose of these exercises is to assess how different is the sensitivity of nominal yields to macroeconomic surprises not only under each informational assumption, imperfect knowledge and rational expectations, but, more importantly, under the assumptions that inflation expectations are anchored or not. As agents do not know the central bank's inflation target under the imperfect knowledge framework, they actually interpret forecast errors as possibly different inflation drift. The main insight to be taken from the present exercise is the model's capability of generating state-dependent and time-varying sensitivity of nominal yields to macroeconomic surprises in that it accounts for different dynamics under anchored and unanchored expectations. In this sense, one important conclusion that follows is that the patterns of sensitivity in the data cannot be matched by any of the features of this model alone (that is, either time-varying risk premia or constant-gain learning). Rather, the passthrough coefficient curve and the volatility curve (conditional on expectations being anchored or not) can only be matched provided with state-dependency in the anchoring of expectations. Finally, something important to note before proceeding with the rest of this chapter is that results on simulations and impulse response functions are not affected in any way by the values estimated for parameters in the observation equation (such as the inflation mean, $\pi^{*}$ ).

\section{1}

\section{Impulse Response Function}

This section addresses the volatility curve conditional on different shocks that hit the economy. Hence, the results here are mostly comparable to those of a news regression in that both point out how much more or how much less

${ }^{1}$ In particular, the formula used to build the $k$-year-ahead one-year forward rate, $f_{k, t}$, is:

$$
1+f_{k, t}=\frac{\left(1+r_{k+1, t}\right)^{k+1}}{\left(1+r_{k, t}\right)^{k}} .
$$


sensitive to shocks are the yields of longer maturities relative to those of shorter ones. The choice to analyze forward rates follows from the fact that the news regressions' literature has mostly focused on these type of rates rather than on the yields themselves as dependent variable. In order to capture the difference between anchored and unanchored expectations, all exercises were repeated under two scenarios. In the first one, inflation expectations are assumed to be anchored, and, thus, the decreasing-gain regime is used since the first period by agents. In the second one, expectations are initially not anchored, hence constant-gain regime is employed temporarily. ${ }^{2}$ In order to assess the impacts that the anchoring of inflation exerts over model dynamics and interest-rates term structure, we consider separately the impacts of the various shocks that may hit the economy. Finally, the parameters of the model were calibrated using the estimated values in the last chapter.

With regard to initial conditions, we set $k_{0}=\bar{g}^{-1}$, but there are qualitative implications to this choice as $k_{0}$ accounts for the starting moment of the learning process under anchored expectations. ${ }^{3}$ Since, in this case, $k_{t}$ evolves monotonically in time (see equation (2-24)), a large $k_{0}$ represents a situation in which the economy began many periods before the exercise, whilst $k_{0}=0$ addresses the case in which the learning process has just begun. The present exercise contrasts model dynamics under anchored inflation expectations to that under unanchored expectations, and the latter scenario is only possible in the hypothetical situation that the economy has been previously hit by a sequence of positive (or negative) shocks (as discussed in Chapter 2). Thus, it is reasonable to allow $k_{0}$ to be larger than 0 and, in particular, choosing $k_{0}=\bar{g}^{-1}$ maintains comparability between anchored and unanchored results.

Figure 4.1 presents the volatility curves of one-year forward rates generated after different shocks hit the economy. The numbers below/above each curve represent the ratio between the standard-deviation of the rate ending in 10 years and that of the rate ending in 2 years, and are in the following format: blue values correspond to the initially anchored expectations case, while yellow represents rational expectations, and red, the unanchored expectations case; bold values are associated with the approximate version of the model. The economy was simulated for 40 periods (equivalent to 10 years) in each case. From Figure 4.1, three main points stand out. First, the overall volatility generated under unanchored expectations is much larger than that under ra-

\footnotetext{
${ }^{2}$ The interpretation is that the economy has previously suffered shocks that forced agents into switching to constant-gain learning.

${ }^{3}$ In that the algorithm under unanchored expectations is initialized with constant-gain learning regime, the value of $k_{0}$ is not relevant.
} 
tional expectations or, more importantly, under anchored expectations. That implies, as would be expected, that the yields of all maturities are much more sensitive to inflation surprises when expectations are unanchored than when they are more stable. Second, the volatility curve may slope downwards when expectations are anchored (blue lines), as opposed to when they are not (red lines), in which case all volatility curves generated are flat. The interpretation is that, whenever expectations are not anchored, yields of longer maturities should respond to inflation surprises at least as strongly as those of shorter ones, but that need not be true in the case of anchored inflation expectations. This insight yields a testable prediction, namely that the coefficients of a news regression to inflation surprises should be not only time-varying, but state-dependent. This state-dependency should be reflected in a coefficient curve (regression coefficients plotted against maturity) that is flatter in times of unanchored expectations than in periods of anchored expectations. Third, the volatility curve tends to be less negatively sloped under anchored expectations than the rational expectations counterpart, although both assumptions yield similar results in terms of level. The intuition here is that whenever expectations are anchored, the economy should move towards the rational expectations equilibrium, for the sensitivity of the estimated inflation target to surprises diminishes over time.

\section{2 \\ Simulations}

This section presents results on simulations of the model, based on the parameters estimated before. With the simulated data, under both rational expectations and subjective beliefs, we perform two exercises. The first is evaluating the volatility of forward rates. The second is running pass-through regressions, similar to those addressed in Chapter 1 . To evaluate the differences from when expectations are anchored to when they are not, we also ran the regressions and computed volatilities separately for the periods with anchored (decreasing-gain regime) and unanchored (constant-gain regime) expectations. Moreover, we also perform all the exercises for the case in which agents learn only with constant gains, a mechanism that has been common in the literature, to separate the gains from switching from rational expectations to subjective beliefs from those of actually considering the anchoring/unanchoring mechanism. We also present results from both true and the approximate models, and perform the same exercises with the original quarterly data. To facilitate the evaluation of our results, we break the original data set in two samples based on Carvalho et al. (2017): 1975-1995, a period of less well 


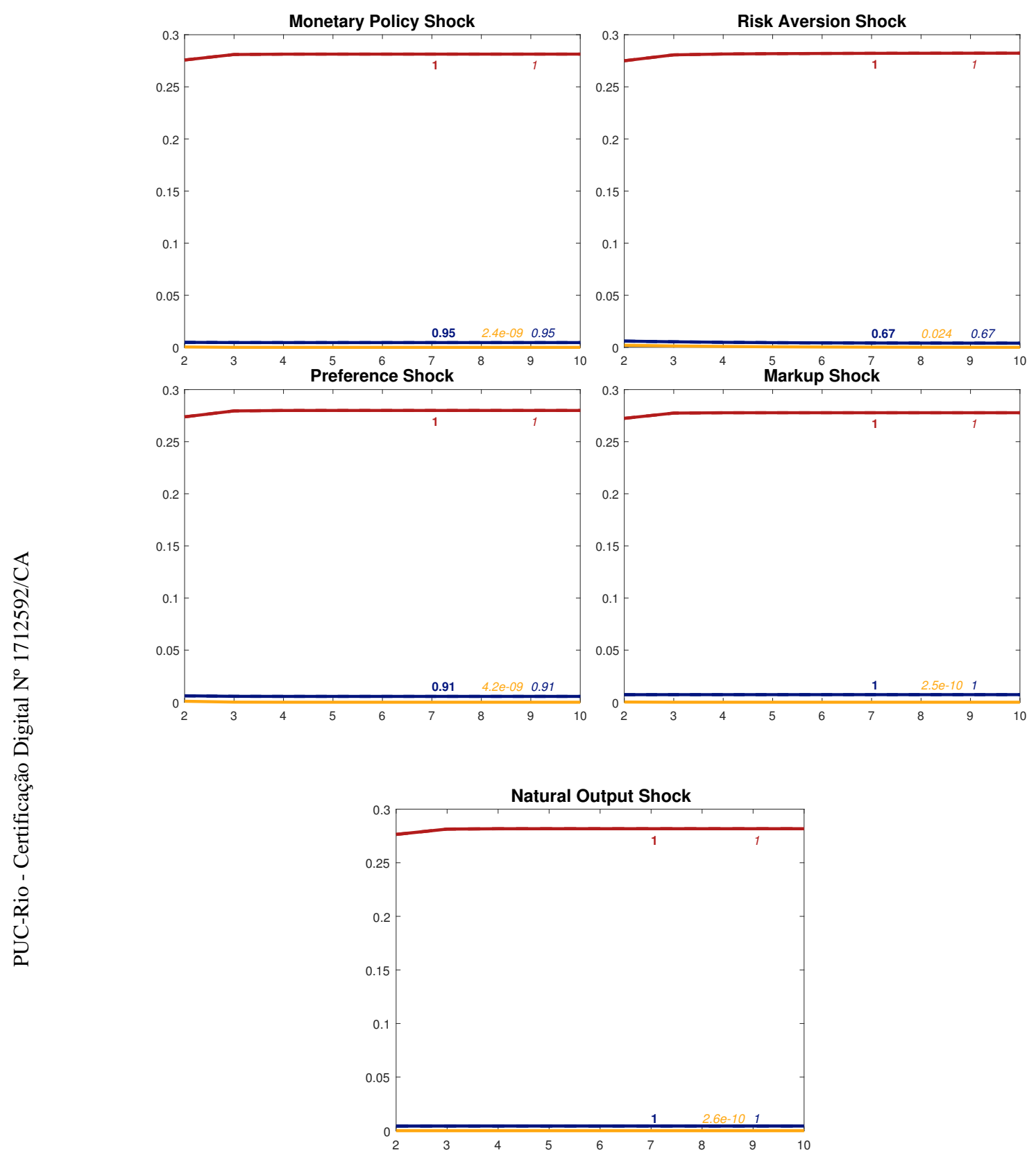

Figure 4.1: Volatility Curves of Forward Rates, Response to Different Shocks. The colored numbers show the ratio between the volatility of the forward-rates ending, respectively, in 10 and in 2 years. The values in bold represent this ratio for the approximate model. 
Table 4.1: Volatility of Forward Rates

\begin{tabular}{|c|c|c|c|c|c|c|c|c|c|c|c|}
\hline \multirow[b]{2}{*}{ Ending Year } & \multicolumn{3}{|c|}{ Data } & \multicolumn{3}{|c|}{ SR Learning, True } & \multicolumn{3}{|c|}{ SR Learning, Approximate } & \multirow{2}{*}{$\begin{array}{l}\text { CG Learning } \\
\text { All Periods }\end{array}$} & \multirow{2}{*}{$\begin{array}{c}\mathrm{RE} \\
\text { All Periods }\end{array}$} \\
\hline & $1975-2006$ & $1996-2006$ & $1975-1995$ & All Periods & Anchored & Unanchored & All Periods & Anchored & Unanchored & & \\
\hline 2 & 8.0203 & 2.0318 & 5.8909 & 2.9666 & 2.8837 & 2.7864 & 2.9660 & 2.8806 & 2.8135 & 8.4549 & 2.6210 \\
\hline 3 & 7.1022 & 1.2642 & 4.9200 & 2.0462 & 1.9425 & 2.5978 & 2.0450 & 1.9384 & 2.6268 & 7.9389 & 1.5676 \\
\hline 4 & 6.4788 & 0.8775 & 4.3275 & 1.6131 & 1.4919 & 2.5419 & 1.6115 & 1.4870 & 2.5705 & 7.7966 & 0.9765 \\
\hline 5 & 5.9912 & 0.6776 & 3.9381 & 1.4022 & 1.2701 & 2.5181 & 1.4005 & 1.2647 & 2.5460 & 7.7437 & 0.6070 \\
\hline 6 & 5.5949 & 0.5681 & 3.6824 & 1.3082 & 1.1706 & 2.5081 & 1.3063 & 1.1649 & 2.5357 & 7.7210 & 0.3771 \\
\hline 7 & 5.2696 & 0.5021 & 3.5150 & 1.2687 & 1.1287 & 2.5042 & 1.2668 & 1.1230 & 2.5322 & 7.7104 & 0.2343 \\
\hline 8 & 5.0154 & 0.4657 & 3.4117 & 1.2527 & 1.1117 & 2.5028 & 1.2508 & 1.1059 & 2.5310 & 7.70 .51 & 0.1455 \\
\hline 9 & 4.8330 & 0.4439 & 3.3581 & 1.2462 & 1.1048 & 2.5023 & 1.2443 & 1.0990 & 2.5306 & 7.7024 & 0.0904 \\
\hline 10 & 4.7033 & 0.4323 & 3.3381 & 1.2436 & 1.1020 & 2.5021 & 1.2417 & 1.0963 & 2.5305 & 7.7009 & 0.0562 \\
\hline Ratio $(10 / 2)$ & 0.5864 & 0.2128 & 0.5667 & 0.4192 & 0.3821 & 0.8980 & 0.4186 & 0.3806 & 0.8994 & 0.9108 & 0.0214 \\
\hline \multicolumn{4}{|c|}{ Anchored Periods (mean) } & \multicolumn{3}{|c|}{498.0} & \multicolumn{3}{|c|}{498.0} & - & - \\
\hline
\end{tabular}

anchored expectations, and 1996-2006, a period of better anchored inflation expectations.

Table 4.1 presents the volatility of forward-rates with different ending years. One thing to note is that although the volatility curve is negatively sloped in all cases, it is much flatter in the case of unanchored expectations and constant-gain learning than in the other two situations. Indeed, notice that the ratio of the standard deviation for the rate ending in 10 years to that ending in 2 years reaches approximately 0.90 in the mentioned cases, whereas it is of only 0.38 and 0.02 under anchored and rational expectations, respectively. Moreover, not only is the curve flatter, as the overall level of volatility is higher under unanchored expectations (and even more so when agents learn solely with constant gains). Although such level of volatility produced is still a bit lower than that observed in the data, results are particularly interesting for they help in explaining the differences observed between the periods selected in Table 4.1. It is worth mentioning that by adding more persistence to the errors in the simulation and, thus, producing an overall result with more unanchored periods, it is possible to increase the level of volatility up to a point that matches better the data. In fact, notice that if expectations were to be unanchored all of the time (only constant-gain learning), the level of volatility produced would be even larger than that of the original data.

Finally, Table 4.2 presents the results of pass-through regressions (that is, regressions with one-year forward rates as dependent variable and the one-year rate as regressor), computed with both the original and the simulated data. The row "Ratio (10/2)" shows the ratios between the coefficient estimated in the regression for the one-year forward rate ending in ten years and that for the forward rate ending in two years, and gives an idea of the slope of the 
Table 4.2: Pass-Through Coefficients

\begin{tabular}{|c|c|c|c|c|c|c|c|c|c|c|c|}
\hline \multirow[b]{2}{*}{ Ending Year } & \multicolumn{3}{|c|}{ Data } & \multicolumn{3}{|c|}{ SR Learning, True } & \multicolumn{3}{|c|}{ SR Learning, Approximate } & \multirow{2}{*}{$\begin{array}{l}\text { CG Learning } \\
\text { All Periods }\end{array}$} & \multirow{2}{*}{$\begin{array}{c}\mathrm{RE} \\
\text { All Period: }\end{array}$} \\
\hline & $1975-2006$ & $1996-2006$ & $1975-1995$ & All Periods & Anchored & Unanchored & All Periods & Anchored & Unanchored & & \\
\hline 2 & 0.7690 & 0.8947 & 0.7550 & 0.9259 & 0.9169 & 0.4930 & 0.9266 & 0.9171 & 0.4587 & 2.2810 & 0.8829 \\
\hline 3 & 0.5865 & 0.6742 & 0.5771 & 0.3103 & 0.2982 & 0.4382 & 0.3113 & 0.2984 & 0.3723 & 2.0196 & 0.2470 \\
\hline 4 & 0.4816 & 0.5138 & 0.4788 & 0.1856 & 0.1729 & 0.4260 & 0.1865 & 0.1732 & 0.3587 & 1.9614 & 0.1180 \\
\hline 5 & 0.4212 & 0.3980 & 0.4249 & 0.1390 & 0.1262 & 0.4209 & 0.1400 & 0.1265 & 0.3548 & 1.9387 & 0.0698 \\
\hline 6 & 0.3845 & 0.3091 & 0.3944 & 0.1132 & 0.1003 & 0.4181 & 0.1142 & 0.1005 & 0.3529 & 1.9259 & 0.0430 \\
\hline 7 & 0.3579 & 0.2369 & 0.3731 & 0.0974 & 0.0845 & 0.4163 & 0.0984 & 0.0847 & 0.3517 & 1.9181 & 0.0267 \\
\hline 8 & 0.3368 & 0.1825 & 0.3560 & 0.0876 & 0.0746 & 0.4152 & 0.0886 & 0.0749 & 0.3510 & 1.9132 & 0.0166 \\
\hline 9 & 0.3166 & 0.1319 & 0.3394 & 0.0815 & 0.0685 & 0.4145 & 0.0825 & 0.0688 & 0.3506 & 1.9102 & 0.0103 \\
\hline 10 & 0.2961 & 0.0945 & 0.3207 & 0.0778 & 0.0648 & 0.4141 & 0.0788 & 0.0650 & 0.3503 & 1.9083 & 0.0064 \\
\hline \multirow[t]{2}{*}{ Ratio $(10 / 2)$} & 0.3850 & 0.1056 & 0.4248 & 0.0840 & 0.0707 & 0.8400 & 0.0850 & 0.0709 & 0.7697 & 0.8366 & 0.0072 \\
\hline & \multicolumn{3}{|c|}{ Anchored Periods (mean) } & & 498.0 & & & 498.0 & & - & - \\
\hline
\end{tabular}

Ratio $(10 / 2)=$ ratio between the estimated coefficients in the regressions for forward rates ending in 10 and in 2 years. The dependent variable in all regressions is the quarterly change in one-year forward rates (with different ending years), and the regressor is the quarterly change in the one-year rate.

SR Learning = switching regime learning (model with anchoring/unanchoring of expectations)

CG Learning $=$ only constant-learning model

$\mathrm{RE}=$ rational expectations

The results with artificial data are based on 5,000 simulations of 500 periods each.

curve. One characteristic that stands out is that while the ratios under rational expectations are very close to zero, they are larger for the case under subjective beliefs. Moreover, ratios tend to be larger when expectations are unanchored or, either, when only constant-gain learning is considered. A second interesting feature of results is that while the pass-through coefficient for shorter rates is larger or at least similar under anchored expectations compared to the unanchored situation, this same coefficient for longer rates is much smaller on the first case. These results seem to match the patterns observed in the data.

Taking together the results from both Tables 4.1 and 4.2, the main insight is that neither the rational expectations assumption nor a sole constant-gain learning regime offer a reasonable explanation for the different shapes of the coefficient and volatility curves over time, whereas the imperfect knowledge framework embedded with a shift between anchored and unanchored expectations seems to do a much better job. 


\section{5}

\section{Conclusion}

This dissertation assessed the impacts of the anchoring of inflation expectations on nominal yield sensitivity to macroeconomic surprises. To that end, a conceptual framework with two main characteristics was presented. First, it accounts for endogenous anchoring of long-run inflation expectations by departing from rational expectations and assuming the learning process proposed in Carvalho et al. (2017). Second, agents face time-varying risk aversion, which allows the model to account for time-varying risk premia. The model was estimated by Simulated Maximum Likelihood, and, on this estimated version of the model, impulse response functions and simulations were assessed. The main result is that the model can produce patterns of volatility and regression coefficients that are consistent with the data on the US and its changes over time. Our framework also generates one main testable prediction, namely that the sensitivity of the term structure to inflation surprises is state-dependent. It is left for future research, however, to empirically verify the mentioned prediction.

There are many ways in which this research could be further extended in the future. First, it would be interesting to adapt the model presented in this dissertation to account for changing real rate expectations, or, at least, to control for those expectations through the measurement equation when estimating the model. Second, the estimated version of the model could be used to perform counterfactual exercises. Finally, the implications of the conceptual framework here presented to the term structure of real bond yields could be analyzed. We also leave for future research the estimation of our model under a two-step procedure, that could potentially improve the fit of the model to the data and generate a historical pattern of anchoring of inflation expectations in line with results in Carvalho et al. (2017). 


\section{Bibliography}

Aguilar, P. and Vazquez, J. (2018). Term structure and real-time learning. Technical report, Working Paper.

Amisano, G. and Tristani, O. (2009). A dsge model of the term structure with regime shifts. Technical report, Working Paper.

Ang, A., Boivin, J., Dong, S., and Loo-Kung, R. (2011). Monetary policy shifts and the term structure. Review of Economic Studies, 78:429 - 457.

Ang, A. and Piazzesi, M. (2003). A no-arbitrage vector autoregression of term structure dynamics with macroeconomic and latent variables. Journal of Monetary Economics, 50:745 - 787.

Ascari, G., Florio, A., and Gobbi, A. (2017). Transparency, expectations anchoring and the inflation target. European Economic Review, 91:261 - 273.

Beechey, M. (2006). A closer look at the sensitivity puzzle: The sensitivity of expected future short rates and term premia to macroeconomic news. Finance and Economics Discussion Series 2007-06, Board of Governors of the Federal Reserve System (U.S.).

Beechey, M. J. and Wright, J. H. (2009). The high-frequency impact of news on long-term yields and forward rates: Is it real? Journal of Monetary Economics, $56: 535-544$.

Bekaert, G., Cho, S., and Moreno, A. (2010). New keynesian macroeconomics and the term structure. Journal of Money, Credit and Banking, 42(1):33 - 62.

Bikbov, R. and Chernov, M. (2013). Monetary policy regimes and the term structure of interest rates. Journal of Econometrics, 174:27 - 43.

Busetti, F., Delle Monache, D., Gerali, A., and Locarno, A. (2017). Trust, but verify. de-anchoring of inflation expectations under learning and heterogeneity. Technical report, European Central Bank.

Carvalho, C., Eusepi, S., Moench, E., and Preston, B. (2017). Anchored inflation expectations. Technical report, Working Paper. 
Christiano, L. J., Motto, R., and Rostagno, M. (2014). Risk shocks. The American Economic Review, 104(1):27 - 65.

Cochrane, J. H. and Piazzezi, M. (2005). Bond risk premia. The American Economic Review, 95(1):138 - 160.

Cogley, T. (2005). Changing beliefs and the term structure of interest rates: Crossequation restrictions with drifting parameters. Review of Economic Dynamics, 8:420 - 451 .

Crump, R., Eusepi, S., and Moench, E. (2016). The term structure of expectations and bond yields. Technical report, Federal Reserve Bank of New York.

De Graeve, F., Emiris, M., and Wouters, R. (2009). A structural decomposition of the us yield curve. Journal of Monetary Economics, 56:545 - 559.

Dew-Becker, I. (2012). Essentially affine approximations for economic models. Technical report, Working Paper.

Dew-Becker, I. (2014). Bond pricing with a time-varying price of risk in an estimated medium-scale bayesian dsge model. Journal of Money, Credit and Banking, 46(5):837 - 888 .

Dewachter, H. and Lyrio, M. (2008). Learning, Macroeconomic Dynamics and the Term Structure of Interest Rates, pages 191-245. University of Chicago Press.

Dewatcher, H., lania, L., and Lyrio, M. (2011). A new-keynesian model of the yield curve with learning dynamics: A bayesian evaluation. Technical report, Working Paper.

Dewatcher, H. and Lyrio, M. (2006). Macro factors and the term structure of interest rates. Journal of Money, Credit and Banking, 38(1):119 - 140.

Dewatcher, H., Lyrio, M., and Maes, K. (2006). A joint model for the term structure of interest rates and the macroeconomy. Journal of Applied Econometrics, $21: 439-462$.

Ehrmann, M., Fratzscher, M., Gürkaynak, R., and Swanson, E. (2011). Convergence and anchoring of yield curves in the euro area. The Review of Economics and Statistics, 93(1):350 - 364.

Emiris, M. (2006). The term structure of interest rates in a dsge model. Technical report, National Bank of Belgium.

Eusepi, S. and Preston, B. (2018). The science of monetary policy: An imperfect knowledge perspective. Journal of Economic Literature, 56(1):3 - 59. 
Evans, G. W. and Honkapohja, S. (2001). Learning and Expectations in Economics. Princeton University Press.

Filipova, K., Audrino, F., and De Giorgi, E. (2014). Monetary policy regimes: Implications for the yield curve and bond pricing. Journal of Financial Economics, 113:427 - 454.

Fuhrer, J. C. (1996). Monetary policy shifts and long-term interest rates. The Quarterly Journal of Economics, 111:1183 - 1209.

Garcia, R., Jondeau, E., and Pelgrin, F. (2014). A macro-finance model of the term structure with time-varying market prices of risk. Technical report, Working Paper.

Garcia, R. and Luger, R. (2012). Risk aversion, intertemporal substitution, and the term structure of interest rates. Journal of Applied Econometrics, 27:1013 -1036 .

Gürkaynak, R., Levin, A., Marder, A., and Swanson, E. (2007a). Inflation targeting and the anchoring of inflation expectations in the western hemisphere. Economic Review, Federal Reserve Bank of San Francisco, pages $25-47$.

Gürkaynak, R., Sack, B., and Swanson, E. (2005). The sensitivity of long-term interest rates to economic news: Evidence and implications for macroeconomic models. The American Economic Review, 95(1):425 - 436.

Gürkaynak, R., Sack, B., and Wright, J. H. (2007b). The u.s. treasury yield curve: 1961 to the present. Journal of Monetary Economics, 54:2291 - 2304.

Gürkaynak, R., Swanson, E., and Levin, A. (2010). Does inflation targeting anchor long-run inflation expectations? evidence from the u.s., uk, and sweden. Journal of the European Economic Association, 8(6):1208 - 1242.

Hanson, S. and Lucca, D.; Wright, J. (2017). The excess sensitivity of long-term rates: A tale of two frequencies. Technical report, Federal Reserve Bank of New York.

Hördahl, P., Tristani, O., and Vestin, D. (2006). A joint econometric model of macroeconomic and term-structure dynamics. Journal of Econometrics, 131:405 $-444$.

Hördahl, P., Tristani, O., and Vestin, D. (2008). The yield curve and macroeconomic dynamics. The Economic Journal, 118:1937 - 1970. 
Ireland, P. (2015). Monetary policy, bond risk premia, and the economy. Journal of Monetary Economics, 76:124 - 140.

Iskrev, N. (2010). Local identification in dsge models. Journal of Monetary Economics, 57:189 - 202.

Kozicki, S. and Tinsley, P. A. (2001). Shifting endpoints in the term structure of interest rates. Journal of Monetary Economics, 47:613 - 652.

Kreps, D. (1998). Anticipated Utility and Dynamic Choice, pages 242-274. Cambridge University Press.

Laubach, T., Tetlow, R. J., and Williams, J. C. (2007). Learning and the role of macroeconomic factors in the term structure of interest rates.

Lindstein, F. and Schön, T. (2013). Backward simulation methods for monte carlo statistical inference. Foundations and Trends in Machine Learning, 6(1):1 - 143.

Milani, F. (2012). The modeling of expectations in empirical dsge models: a survey. Technical report, University of California-Irvine, Department of Economics.

Milani, F. (2014). Learning and time-varying macroeconomic volatility. Journal of Economic Dynamics \& Control, 47(1):94 - 114.

Orphanides, A. and Wei, M. (2012). Evolving macroeconomic perceptions and the term structure of interest rates. Journal of Economic Dynamics Control, 36:239 -254 .

Piazzesi, M. and Schneider, M. (2007). Equilibrium Yield Curves, pages 389-472. MIT Press.

Piazzezi, M.; Salomao, J. S. M. (2015). Trend and cycle in bond premia. Technical report, Working Paper.

Preston, B. (2005). Learning about monetary policy rules when long-horizon expectations matter. International Journal of Central Baking, 1(2):81 - 126.

Rotemberg, J. J. (1982). Monopolistic price adjustment and aggregate output. Review of Economic Studies, pages 517 - 531.

Rudebusch, G. and Swanson, E. (2008). Examining the bond premium puzzle with a dsge model. Journal of Monetary Economics, 55:111 - 126.

Rudebusch, G. and Swanson, E. (2012). The bond premium in a dsge model with long-run real and nominal risks. American Economic Journal: Macroeconomics, 4(1):105 - 143 . 
Rudebusch, G. and Wu, T. (2008). A macro-finance model of the term structure, monetary policy and the economy. The Economic Journal, 118:906 - 926.

Shiller, R. J. (1979). The volatility of long-term interest rates and expectations models of the term structure. Journal of Political Economy, 87(6):1190 - 1219.

Sinha, A. (2016). Learning and the yield curve. Journal of Money, Credit and Banking, 48(2-3):513 - 547.

Swanson, E. and Williams, J. C. (2014). Measuring the effect of the zero lower bound on medium- and longer-term interest rates. The American Economic Review, 104(10):3154 - 3185.

Woodford, M. (2003). Interest, and Prices: Foundations of a Theory of Monetary Policy. Princeton University Press.

Wright, J. (2011). Term premia and inflation uncertainty: Empirical evidence from an international panel dataset. The American Economic Review, 101:1514 1534.

$\mathrm{Wu}, \mathrm{T}$. (2006). Macro factors and the affine term structure of interest rates. Journal of Money, Credit and Banking, 38(7):1847 - 1875. 
A

\section{Empirical Evidence}
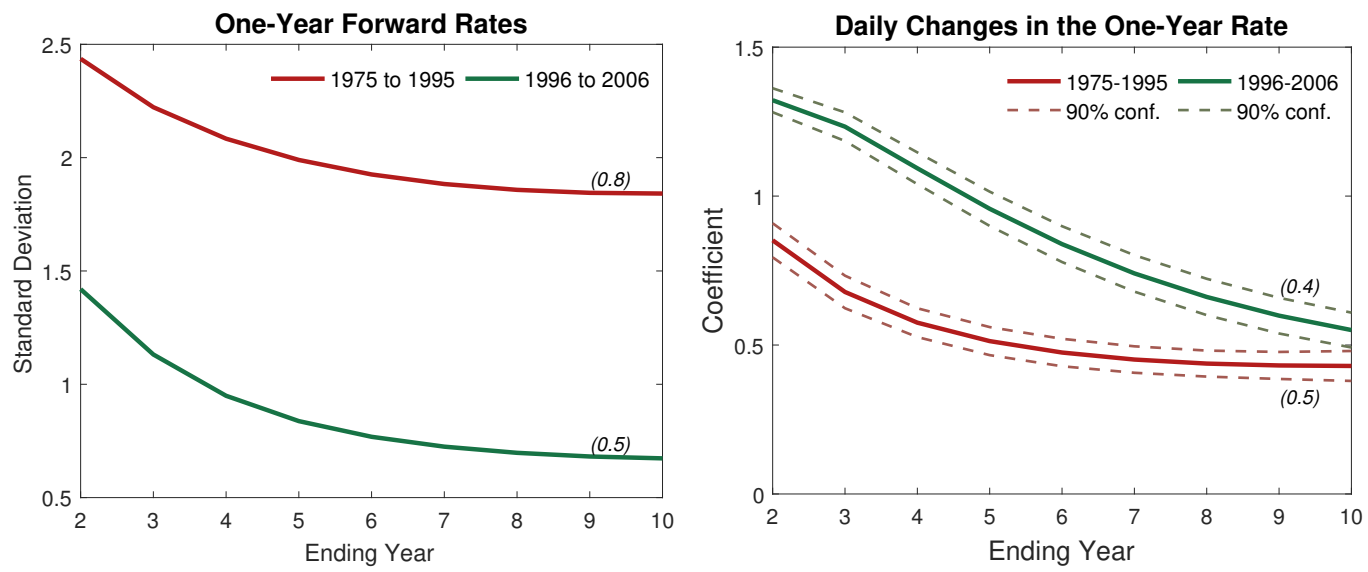

Panel (A)

Panel (B).

() ratio between the standard deviation of the one-year forward rates ending in 9 and in 2 years. Daily data, $\mathrm{jan} / 1975$ to $\mathrm{dec} / 2006$.

() ratio between the coefficients estimated in the regressions Source: US Nominal Zero-Coupon Yields for forward rates ending, respectively, in 10 and in 2 years. Dependent Variable: daily changes in one-year forward rates (different ending years). Regressor: daily changes in the oneyear spot rate. Huber-White standard errors.

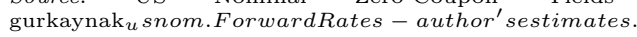

Figure A.1: Empirical Evidence, US, Daily Data 
B

\section{Approximate Model}

\section{B.1}

\section{Deriving the Approximate Model}

$$
f_{k}\left(k_{t-1}, \bar{\pi}_{t-1}\right) \equiv k_{t}=I\left(\bar{\pi}_{t-1}\right)\left(k_{t-1}+1\right)+\left[1-I\left(\bar{\pi}_{t-1}\right)\right] \bar{g}^{-1},
$$

where

$$
I\left(\bar{\pi}_{t-1}\right)=\left\{\begin{array}{cc}
1 & \text { if } \quad\left|\hat{\mathbb{E}}_{t-1} \pi_{t}-E_{t-1} \pi_{t}\right| \leq \nu \sigma^{\eta} . \\
0 & \text { otherwise }
\end{array}\right.
$$

$$
\begin{gathered}
f_{t-1}=\pi_{t-1}-\hat{\mathbb{E}}_{t-2} \pi_{t-1}=\Gamma_{\pi}(\tilde{C}-C)+\Gamma_{\pi}(\tilde{\Theta}-\Theta)+\Gamma_{\pi} \tilde{\Psi} \varepsilon_{t-1} \\
\bar{\pi}_{t}=\bar{\pi}_{t-1}+k_{t}^{-1} f_{t-1}=c_{\pi}\left(k_{t-1}, \bar{\pi}_{t-1}\right)+a_{\pi}\left(k_{t-1}, \bar{\pi}_{t-1}\right) \xi_{t-1},
\end{gathered}
$$

where

$$
c_{\pi}\left(k_{t-1}, \bar{\pi}_{t-1}\right) \equiv\left[1+f_{k}\left(k_{t-1}, \bar{\pi}_{t-1}\right)^{-1} \Gamma_{\pi}(\tilde{\Theta}-\Theta)\right] \bar{\pi}_{t-1}+f_{k}\left(k_{t-1}, \bar{\pi}_{t-1}\right)^{-1} \Gamma_{\pi}(\tilde{C}-C),
$$

$$
a_{\pi}\left(k_{t-1}, \bar{\pi}_{t-1}\right) \equiv\left[f_{k}\left(k_{t-1}, \bar{\pi}_{t-1}\right)^{-1}, 0\right]
$$

and, considering $\eta_{t} \equiv \Gamma_{\pi} \tilde{\Psi} \varepsilon_{t}$,

$$
\begin{gathered}
\xi_{t} \equiv\left[\begin{array}{c}
\eta_{t} \\
\hat{X}_{t,-\mu}
\end{array}\right]=c_{\xi}\left(k_{t-1}, \bar{\pi}_{t-1}\right)+a_{\xi}\left(k_{t-1}, \bar{\pi}_{t-1}\right) \xi_{t-1}+S_{\xi} \varepsilon_{t}, \\
c_{\xi}\left(k_{t-1}, \bar{\pi}_{t-1}\right) \equiv\left[\begin{array}{c}
0 \\
\tilde{C}+\tilde{\Theta} c_{\pi}\left(k_{t-1}, \bar{\pi}_{t-1}\right)
\end{array}\right] \\
a_{\xi}\left(k_{t-1}, \bar{\pi}_{t-1}\right) \equiv\left[\begin{array}{cc}
0 & 0 \\
\tilde{\Theta} f_{k}\left(k_{t-1}, \bar{\pi}_{t-1}\right)^{-1} & \tilde{\Theta}
\end{array}\right]
\end{gathered}
$$




$$
S_{\xi} \equiv\left[\begin{array}{l}
\Gamma_{\pi} \tilde{\Psi} \\
\tilde{\Psi}_{-\mu}
\end{array}\right]
$$

\section{B.2}

\section{The Measurement Equation}

Given the assumptions is Chapter 2, we have, from the statistical model,

$$
\begin{aligned}
& \hat{E}_{t} \hat{X}_{T}=\hat{E}_{t}\left[C+\Phi \hat{X}_{T-1}+\Psi u_{T}+\Theta \bar{\pi}_{T}\right]= \\
& \quad=(I-\Phi)^{-1}\left(I-\Phi^{T-t}\right)\left(C+\Theta \bar{\pi}_{t}\right)+\Phi^{T-t} \hat{X}_{t} .
\end{aligned}
$$

The vector $Y_{t}$, which contains observed data, is defined as

$$
Y_{t}=\left[\begin{array}{c}
\pi_{t} \\
E_{t}^{L I V_{1}}\left(\frac{1}{2} \pi_{t+1}+\frac{1}{2} \pi_{t+2}\right) \\
E_{t}^{L I V_{2}}\left(\frac{1}{2} \pi_{t+1}+\frac{1}{2} \pi_{t+2}\right) \\
E_{t}^{S P F} \pi_{t+1} \\
E_{t}^{S P F} \pi_{t+2} \\
y_{t} \\
i_{t} \\
r_{4, t} \\
r_{8, t} \\
r_{12, t} \\
r_{20, t} \\
r_{40, t}
\end{array}\right]=h_{0, t}+h_{\pi, t} \bar{\pi}_{t}+H_{t}^{\prime} \xi_{t}+R_{t}^{\frac{1}{2}} e_{t}^{o},
$$

and the measurement equation is

$$
Y_{t}=h_{0, t}+h_{\pi, t} \bar{\pi}_{t}+H_{t}^{\prime} \xi_{t}+R_{t}^{\frac{1}{2}} e_{t}^{o}
$$

where 


$$
\begin{aligned}
& h_{0}=T_{y}\left[\begin{array}{c}
\pi^{*} \\
\pi^{*}+\frac{1}{2}\left(\Omega+\Gamma_{\pi}\right) C \\
\pi^{*}+\frac{1}{2}\left(\Omega+\Gamma_{\pi}\right) C \\
\pi^{*}+\Gamma_{\pi} C \\
\pi^{*}+\Omega C \\
0 \\
-A_{1} \\
-\frac{1}{4} A_{4} \\
-\frac{1}{8} A_{8} \\
-\frac{1}{12} A_{12} \\
-\frac{1}{20} A_{20} \\
-\frac{1}{40} A_{40}
\end{array}\right], h_{\bar{\pi}}=T_{y}\left[\begin{array}{c}
0 \\
\frac{1}{2}\left(\Omega+\Gamma_{\pi}\right) \Theta \\
\frac{1}{2}\left(\Omega+\Gamma_{\pi}\right) \Theta \\
\Gamma_{\pi} \Theta \\
\Omega \Theta \\
0 \\
-C_{1} \\
-\frac{1}{4} C_{4} \\
-\frac{1}{8} C_{8} \\
-\frac{1}{12} C_{12} \\
-\frac{1}{20} C_{20} \\
-\frac{1}{40} C_{40}
\end{array}\right],
\end{aligned}
$$

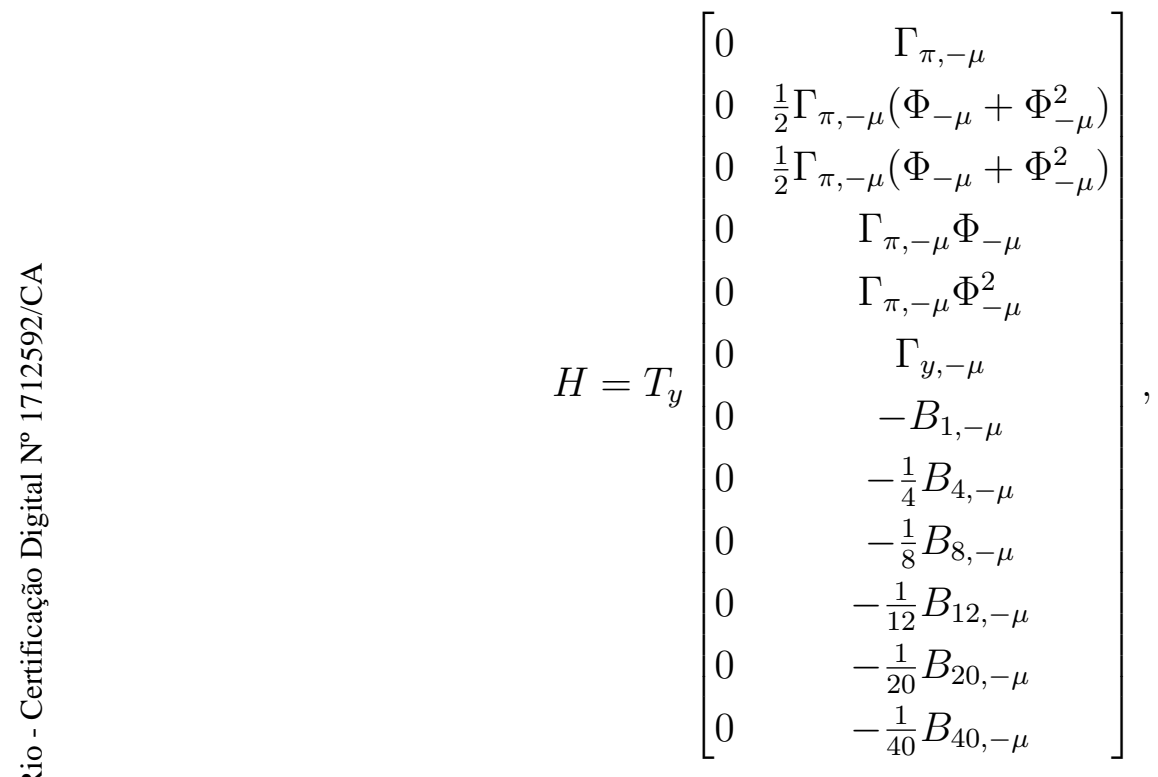

and $T_{y}=4$, and $\Omega=\Gamma_{\pi}\left((I-\Phi)^{-1}\left(I-\Phi^{2}\right)\right)$.

B.3

Term Premia, Simulations and Impulse Response Function 

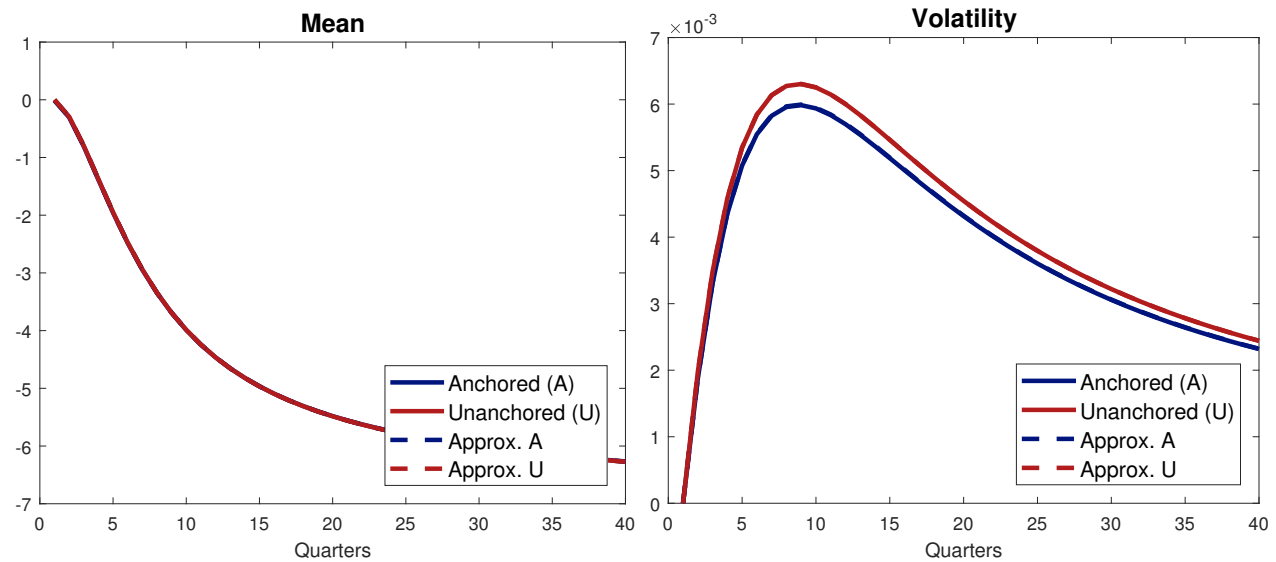

Figure B.1: Term Premia, Moments (1,000 simulations of 500 periods each)
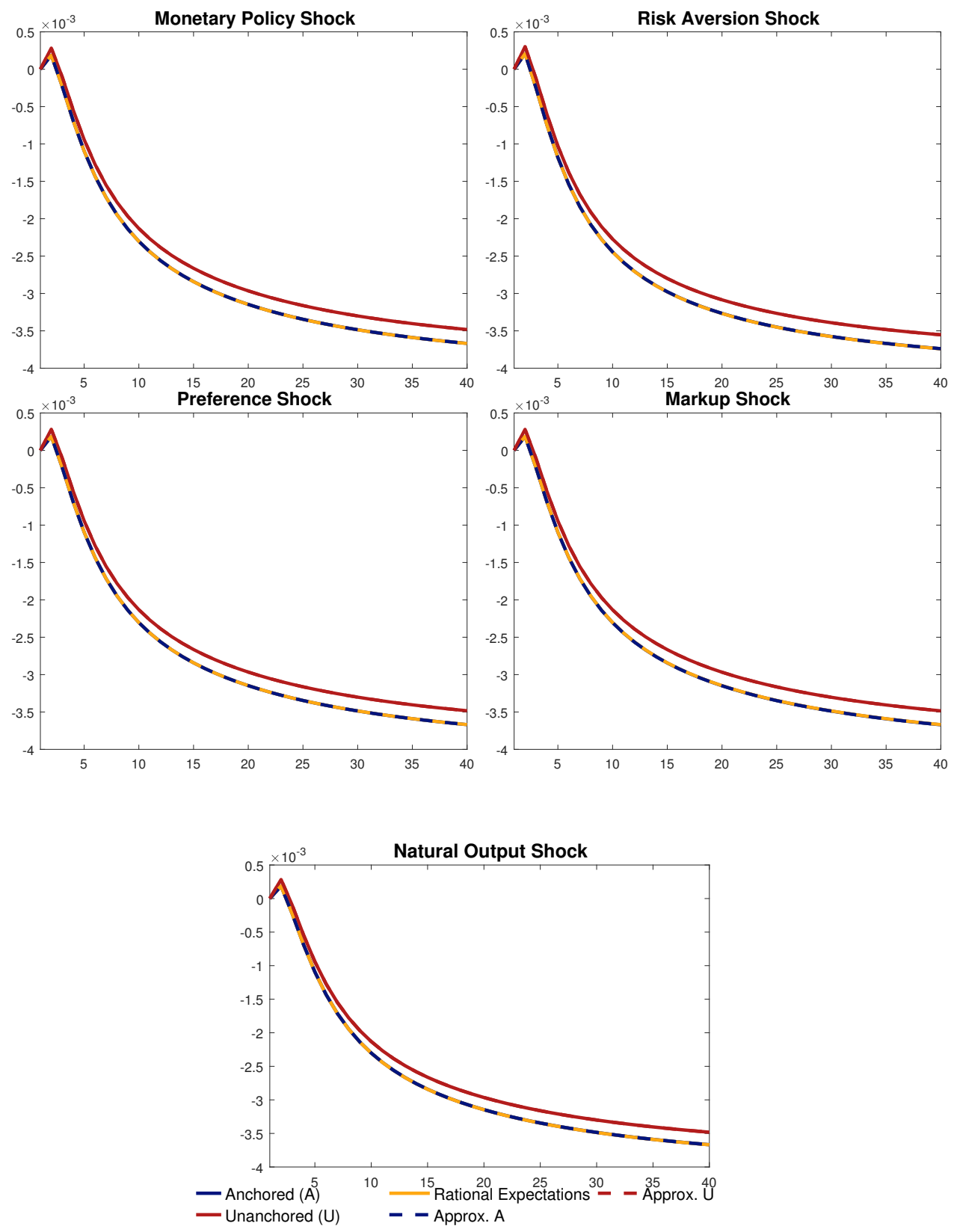

Figure B.2: Term Premia, Response to Different Shocks 
B.4

Structural Innovations (Smoothed Predictions) 

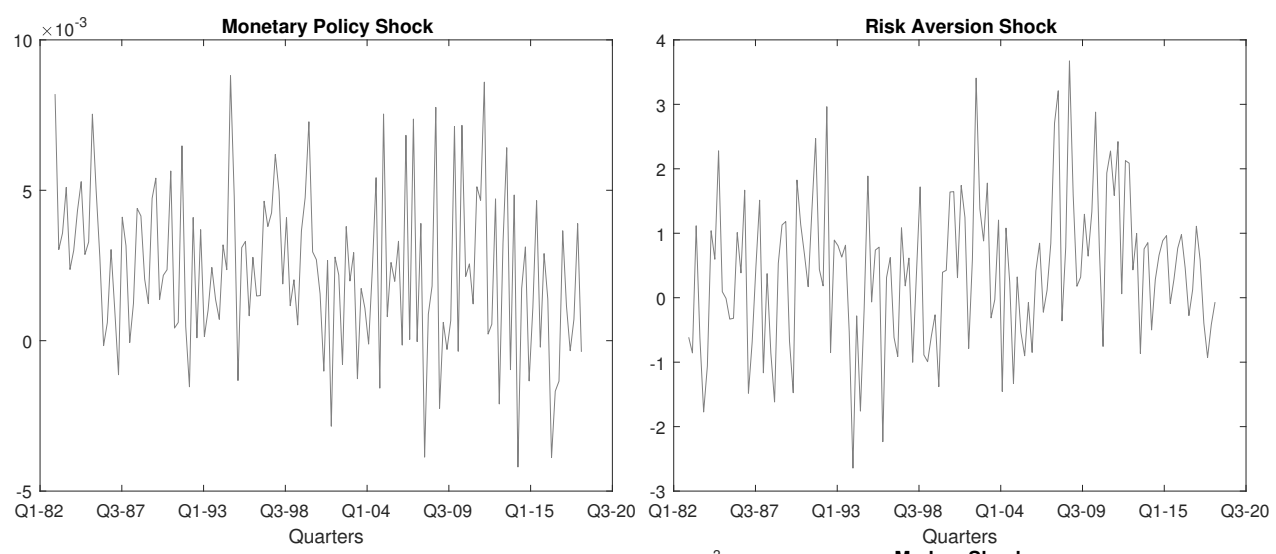

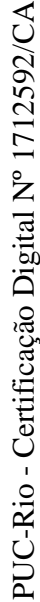
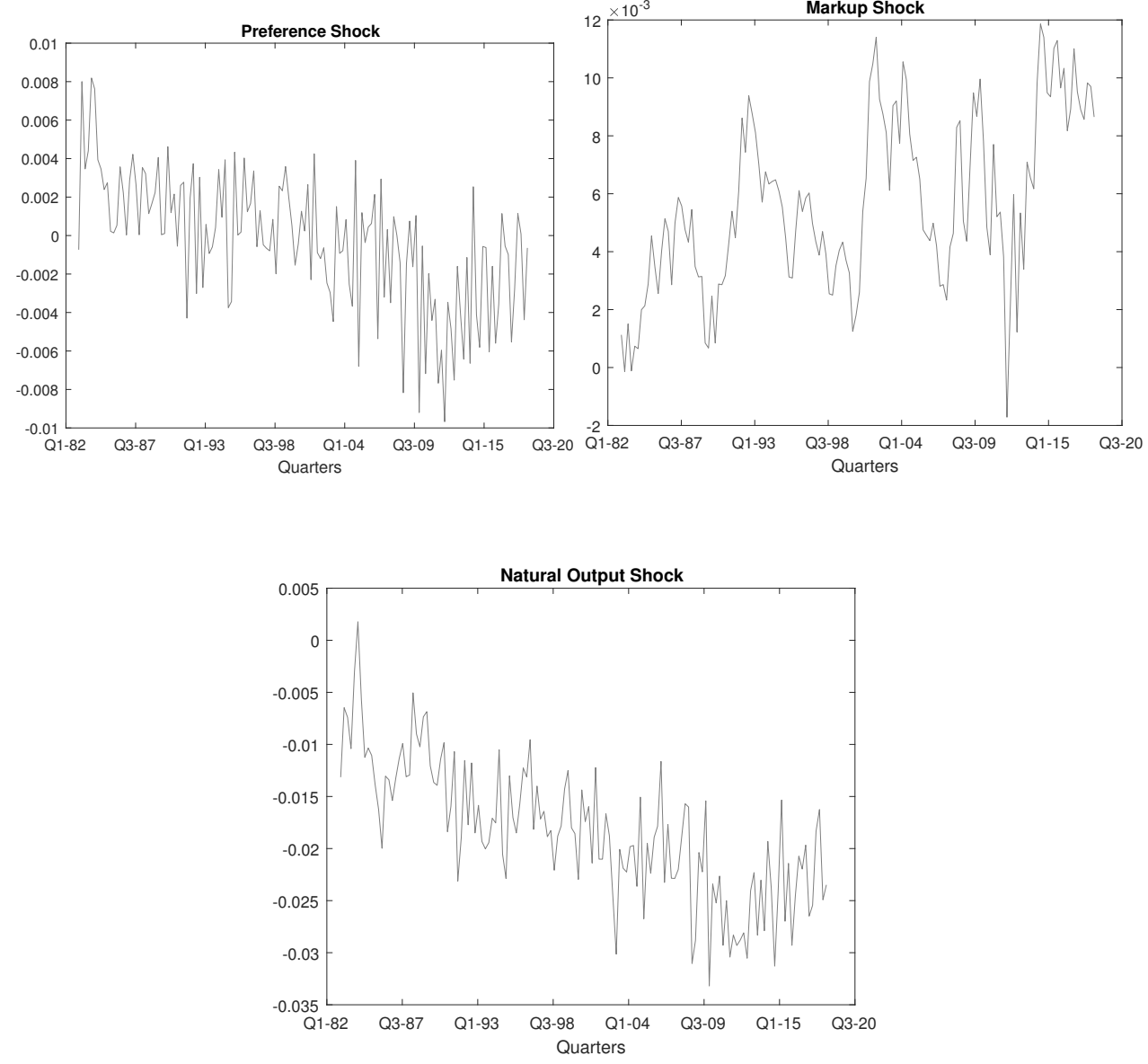

Figure B.3: Structural Shocks, Estimation 